\title{
Humanitarian health programming and monitoring in inaccessible conflict settings: a literature review
}

\author{
Simran Chaudhri ${ }^{1 *}$ D, Kristina Cordes ${ }^{2}$, Nathan Miller ${ }^{1}$ and the Global Health Cluster Remote Programming and \\ Monitoring Task Team
}

\begin{abstract}
Increasing global conflicts and risk to humanitarian aid workers have necessitated innovative approaches to deliver humanitarian assistance. Remotely managed operations aim to continue the provision of services where grave risk to expatriate staff and restrictions by authorities inhibit access. This review of peer-reviewed and gray literature identified these remote approaches and collated lessons learned and best practices for humanitarian health programming and monitoring in inaccessible conflict settings. Analysis identified key principles, including the importance of capacity building and frequent communication, comprehensively assessing and addressing the risks to national staff, increasing monitoring and evaluation efforts despite difficult conditions, and planning for the possibility of a transition to remote programming and having an exit strategy to prevent falling into the remote operations trap. Evidence on how to effectively carry out remote operations is limited; rigorous documentation and evaluation of remotely managed humanitarian operations are required to further build the evidence base.
\end{abstract}

Keywords: Remote management, Remote operations, Inaccessible, Conflict, Emergency, Program, Monitor

\section{Background}

While the end of the Cold War saw a decline in conflicts affecting multiple countries, since 2013 there has been a rise in both number of conflicts and battle casualties (Gates et al. 2016). Humanitarian aid workers have been increasingly targeted in conflict; there were 190 attacks on aid workers in 2014, resulting in 121 deaths. This is three times the 2004 number of 63 incidents (with 56 deaths) (Aid Worker Security Database 2014). International actors are often preferred as kidnapping victims as they provide both a higher ransom and a more visible political statement (Stoddard et al. 2009). Adherence to humanitarian principles and relying on the strategy of "acceptance" no longer ensure safe access for humanitarian actors (Cunningham 2017; Donini and Maxwell 2013). The need to maximize the safety of staff results in reduced access for humanitarian programming and monitoring. This access is further limited by restrictions imposed by both governments and non-state actors

\footnotetext{
* Correspondence: simran.chaudhri@gmail.com

${ }^{1}$ UNICEF New York 3 United Nations Plaza, New York, NY 10017, USA

Full list of author information is available at the end of the article
}

seeking to exercise control over territories (Stoddard et al. 2010).

When the risk to international organizations working in conflict zones becomes too great or access is severely restricted, they are often left no other choice than to remove themselves from the situation. Retreat to fortified compounds or withdrawal from the field results in significant gaps in programs and services, as well as a growing divide between international organizations and local communities (Duffield 2012). This has a harmful effect on local populations who are forced to remain without any support. To address this gap, international organizations may turn to remote management of programs. Remote management has previously been defined as "the withdrawal of senior international or national humanitarian managers from the location of the provision of assistance or other humanitarian action which represents an adaptation to insecurity and a deviation from 'normal' programming practice" (Donini and Maxwell 2013, p. 384). Remote programming aims to continue the provision of services while operating under the assumption that local actors, through their greater 
knowledge of local context and acceptance in the community, and with the continued support from international organizations, are able to provide services at a reduced level of risk than that faced by international staff (Donini and Maxwell 2013; Kalkman 2018). In some situations where grave risk prevents access for expatriate staff from international organizations and national staff from national and international organizations, remote programs are executed and managed by local actors from communities.

This review was conducted in response to an urgent request from the Global Health Cluster to provide evidence on health and nutrition programming and monitoring in inaccessible conflict-affected areas and aims to identify these remote approaches, collating lessons learned, and best practices. While humanitarian programming and monitoring in inaccessible areas has been required in several recent conflicts, it is has largely been governed by trial and error due to lack of comprehensive instruction and detailed strategy. The increasing use of remote operations has shifted the perception of risk and has normalized remote approaches to some extent. This has led to novel challenges and can maintain or widen the divide between aid agencies and recipients (Andersson and Weigand 2015; Duffield 2012; Fisher 2017; Kalkman 2018). This review hopes to inform the creation of formal evidence-based guidance to support future humanitarian initiatives in these settings.

\section{Methods}

This literature review was completed in two parts: a systematic review of peer-reviewed published articles and a search of gray literature sources. Both parts were completed using consensus methodology by two independent researchers from the United Nations Children's Fund (UNICEF) and the US Centers for Disease Control and Prevention (CDC).

\section{Inclusion and exclusion criteria}

English language articles published in peer-reviewed journals between January 1, 1990 and March 1, 2016 (inclusive) were included. Included studies met the following criteria: described real-world humanitarian operations delivering health and nutrition interventions, and took place in an inaccessible location in conflict or natural disaster. Humanitarian programming in natural disasters was included with the aim of identifying novel strategies that could be translated to an inaccessible conflict setting; however, none were identified. Exclusion criteria were as follows: technology or methods described as having a potential humanitarian application but not yet implemented (including simulations), technology or methods used in an inaccessible development context (rather than in response to an emergency), studies with no specific intervention or outcomes, studies that examine preparedness or resilience not linked to response, and review papers; however, references of review papers were screened for primary data sources. Given the burgeoning nature of this field and the limited published literature on the topic, all study designs were considered.

\section{Systematic review of published peer-reviewed literature Search strategy and results}

One search string (Table 1) was entered into six search engines: PubMed, Scopus, MEDLINE/Ovid, Web of Science, Cochrane, and EMBASE. All search results were exported to the online systematic review organizer Covidence. Then, 1853 titles and abstracts were screened, followed by the full text screening of 63 studies. References of all 63 studies that progressed to full text review were also screened to identify primary sources.

Fourteen papers were identified as meeting all criteria and included in this review (Fig. 1). The breakdown by study design was as follows: four retrospective analyses of programs, one retrospective analysis of populations, five descriptive case studies, one case series, two cross-sectional surveys, and one before-and-after study.

\section{Quality assessment}

A checklist adapted from the Strengthening the Reporting of Observational Studies in Epidemiology (STROBE) criteria was used for quality assessment of observational studies, resulting in a rating of high, moderate, or low quality (Blanchet and Roberts 2015). The one qualitative study (Kevany et al. 2014) was assessed using the Critical Appraisals Skills Programme (CASP) checklist (CASP 2013), with a score of 1-4 considered low, 5-8 moderate, and 9-10 (out of 10) high. The case series study(Shanks et al. 2012) was assessed using the NIH Quality Assessment Tool for Case Series (NIH 2014), with a score of 1-3 considered low, 4-6 moderate, and 7-9 high (out of 9). Given the lack of a validated tool, the quality of descriptive case studies could not be formally assessed.

Upon quality assessment, two studies were found to be low, six were moderate, and one was high; five studies were not assessed due to the lack of an appropriate validated tool. Assessment was performed in order to draw conclusions about the quality of the current evidence; given the limited number of published studies, none were excluded based on rating. A table summarizing the

Table 1 Peer-reviewed literature search strings

1. (humanitarian OR crisis OR conflict OR disaster) AND (remote OR inaccessible) AND (Health OR nutrition OR polio OR wash OR trauma OR obstetric) 


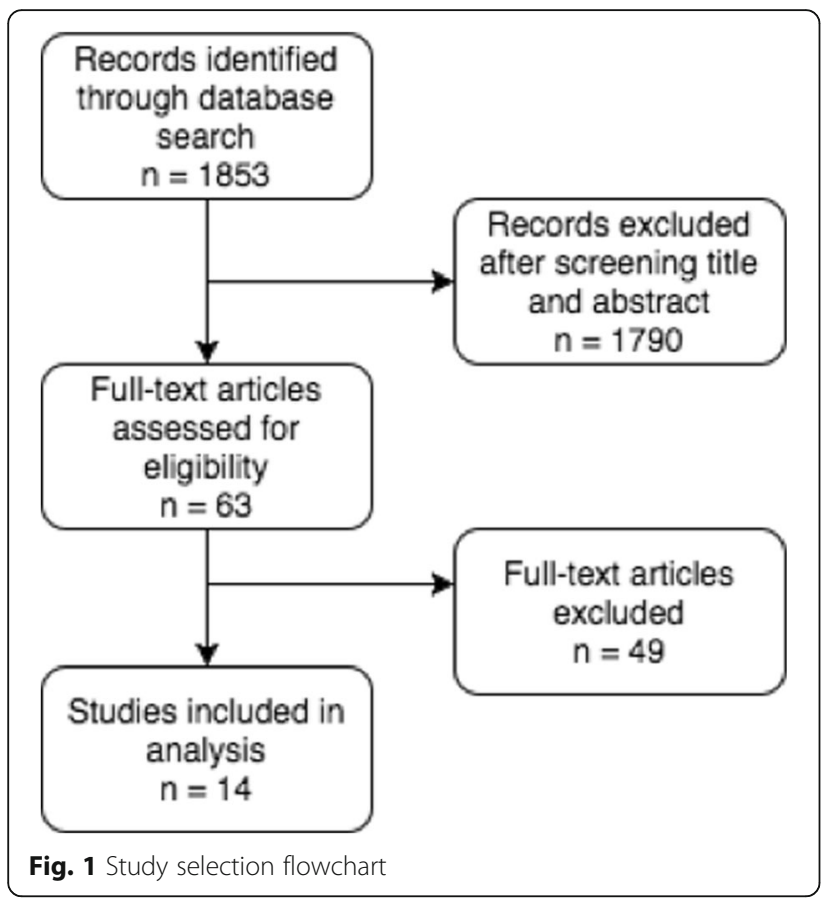

articles included and their corresponding quality assessments can be found in Table 2 .

\section{Review of gray literature \\ Search strategy and results}

The gray literature search included all sources that were not published in peer-reviewed journals, some examples of document types are organizational guidelines, programming notes, program evaluations, presentations, and meeting notes. In addition to a Google search, a call for resources was sent out to humanitarian organizations, with additional contacts obtained via snowball sampling. Contacts were asked to provide any gray literature sources pertaining to humanitarian programming and monitoring in inaccessible areas from their organization or elsewhere. References of documents received were also screened for additional primary sources.

Two researchers screened all resources and consensus was reached on which were relevant and would be included. Then, 131 total documents were reviewed using the same inclusion and exclusion criteria as the peer reviewed literature, with 55 documents proceeding to in-depth analysis and included in the final report. The main reasons for exclusion were documents pertained to emergency settings but did not specifically discuss operations in inaccessible contexts within these settings, documents cited longer term development interventions that were not immediate aid relief, and documents outlined remote operations but not within emergency settings.

\section{Analysis}

Both researchers performed thematic analysis independently. Documents were reviewed and coded based on a defined set of codes created following the initial review; code conflicts were discussed until consensus on which code to include was reached. For example, after a document was reviewed and manually coded by reviewers 1 and 2 independently, it was exchanged between the reviewers who then compared codes and noted discrepancies. The reviewers then met online using a videophone application to review and reach consensus on all discrepancies. Examples and excerpts where then grouped into themes and included in the relevant sub-sections of the final report.

\section{Results}

Causes and motivators of remote operations

The main causes of reduced access include general insecurity or a specific security incident, and restrictions on the movement of aid workers imposed by authorities in power. Additional factors that contribute to limited access include weak international support or pressure to negotiate access with host states, tendency toward risk avoidance over risk management, and poor infrastructure requiring expensive airlift capacity (Stoddard et al. 2006).

Several studies identified factors that need to be considered when determining whether to switch to remote operations. The first is the level and predicted length of insecurity; if the security risk is perceived as temporary, it may be more feasible to close the program and resume when the setting has become secured. The size of the program must be considered, with large programs harder to hand over than smaller programs. This may cause an organization to reduce services and hand over a scaled-back version of the program in order to maintain presence in a location. Feasibility also plays a role in choosing to operate remotely; activities for certain sectors can be more or less feasible based on security or capacity of local staff (for example, highly insecure road travel may make distribution of food aid less feasible). Feasibility will also be governed by an organization's operational history in a specific context. This ties into context considerations where the range, quality, and capacity of local partners must be considered, as well as their ability to operate freely in a region. Finally, the level of vulnerability and need is also a major consideration when debating the shift to remote programming, with organizations frequently opting to provide a program with reduced quality, monitoring and impact, rather than no support at all (Rogers 2006; Stoddard et al. 2006; Stoddard et al. 2010).

The primary benefit of remote programming and monitoring is the continuation of assistance, services, 


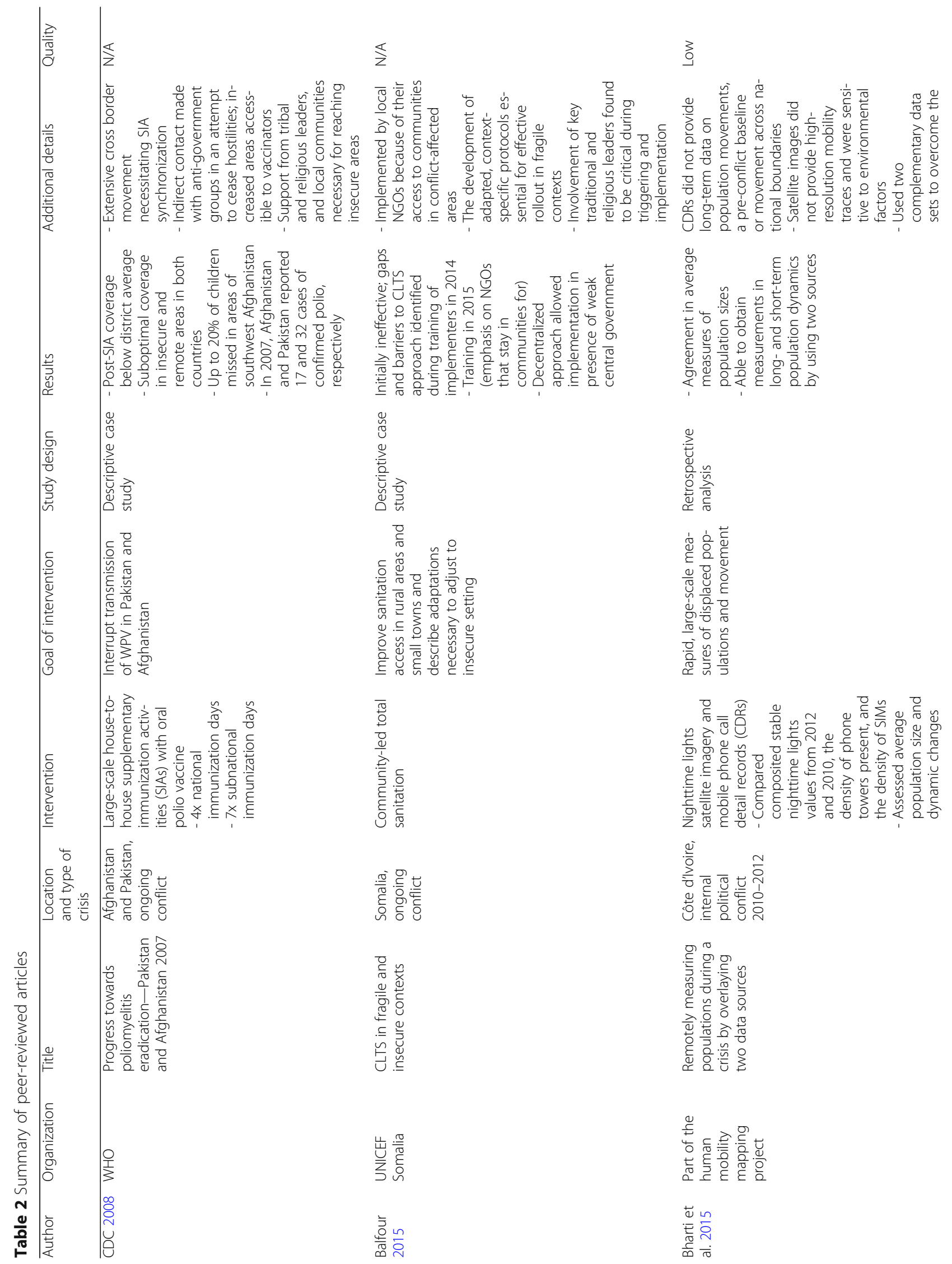




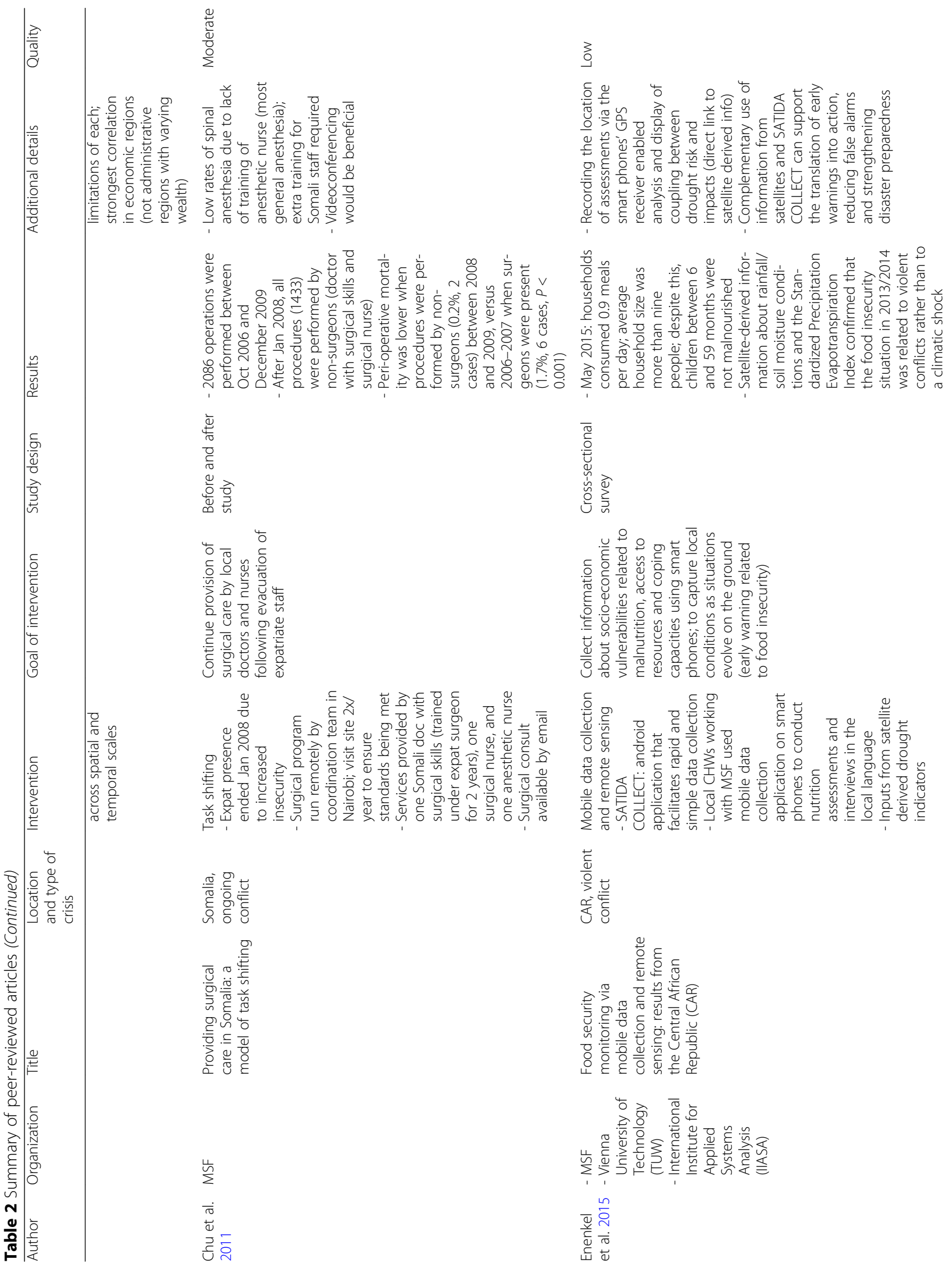




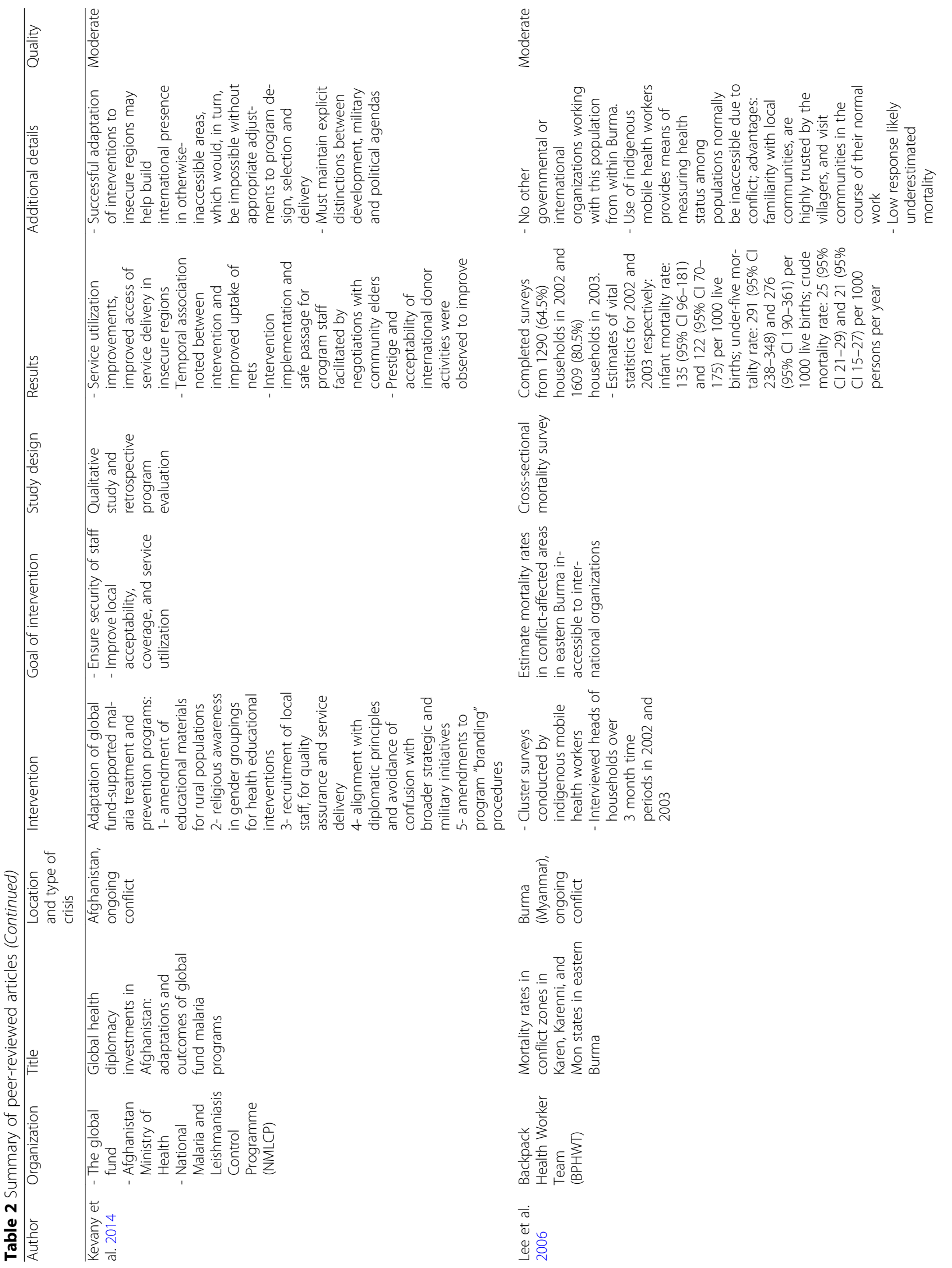




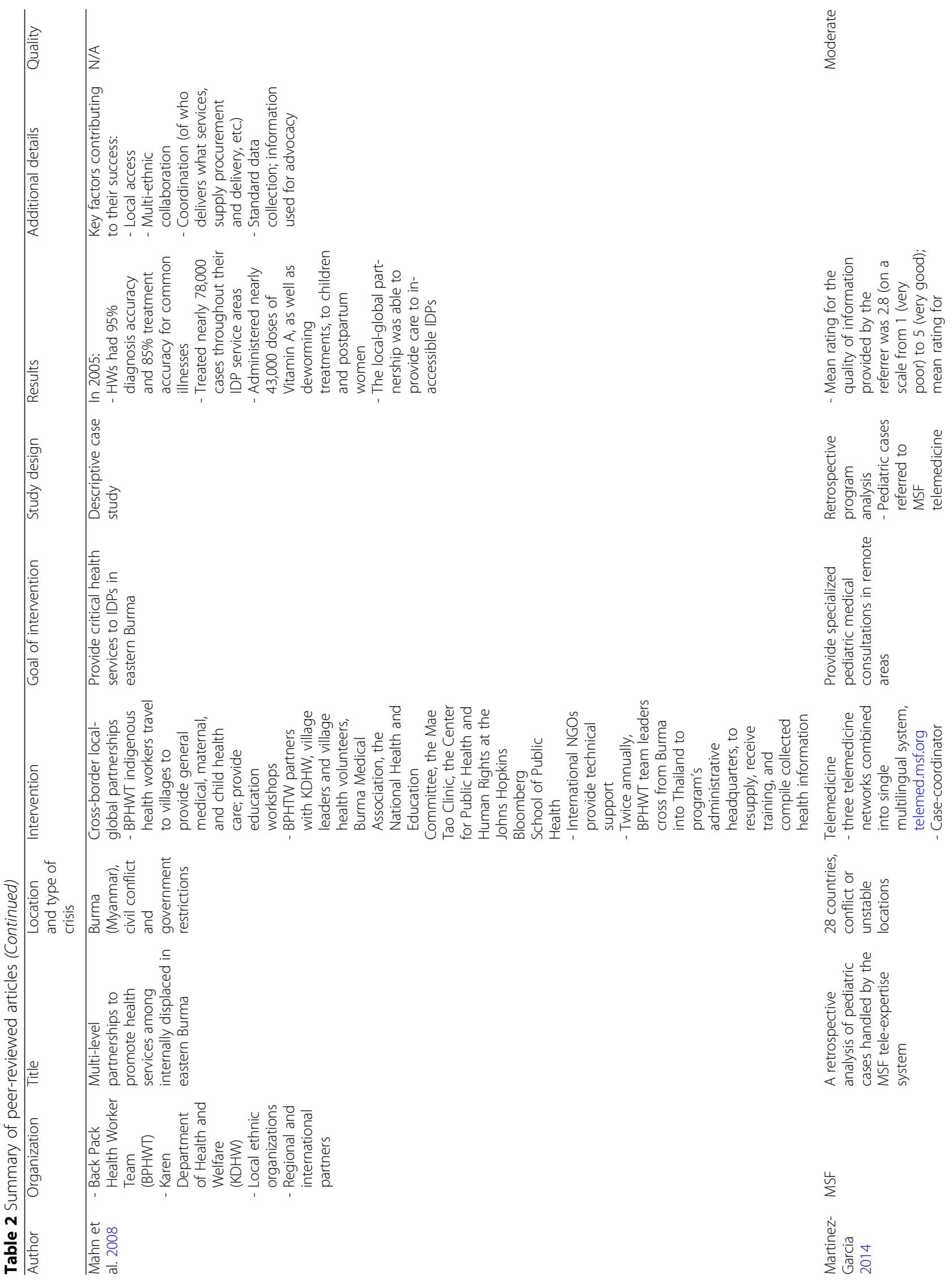




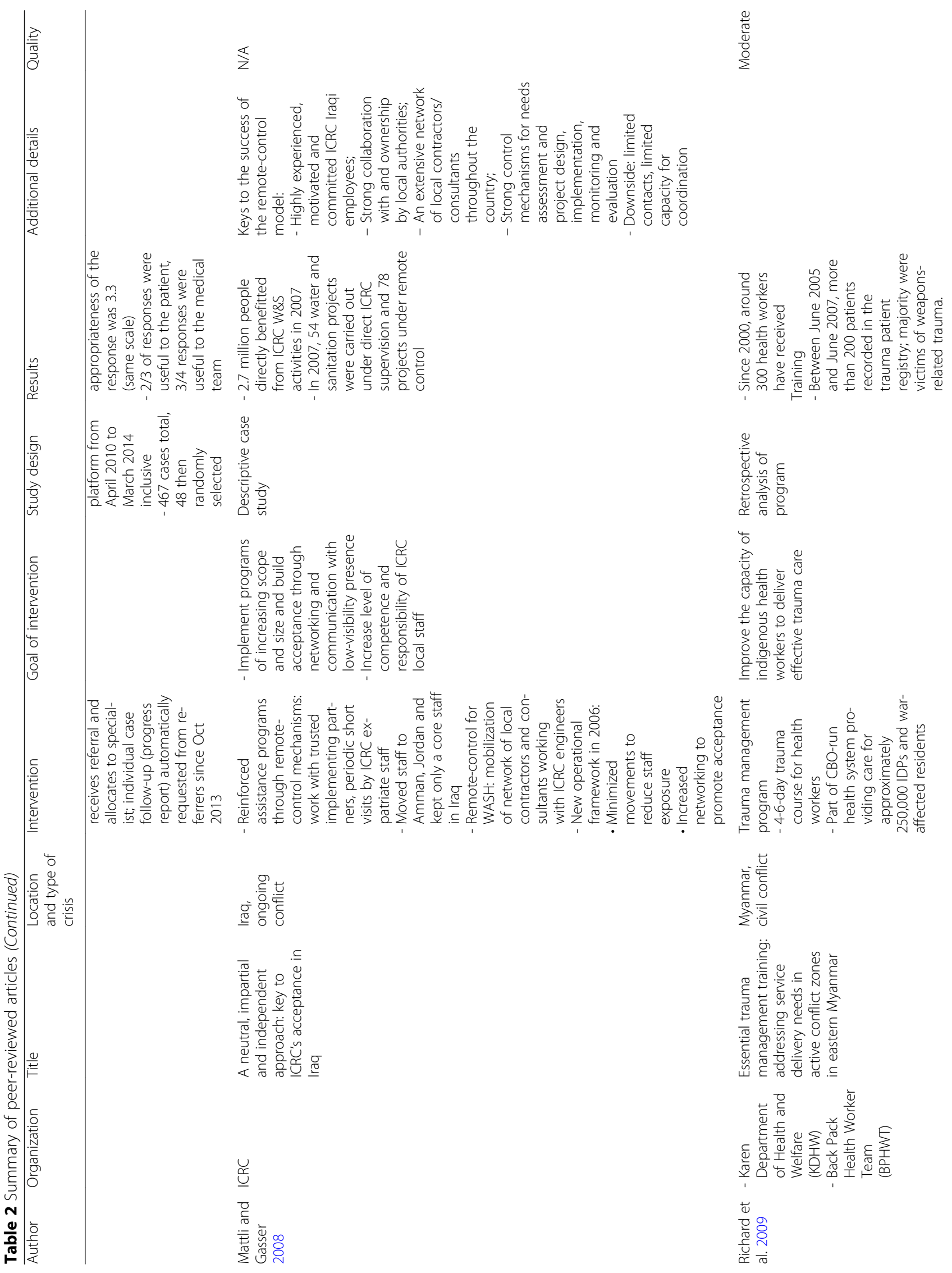




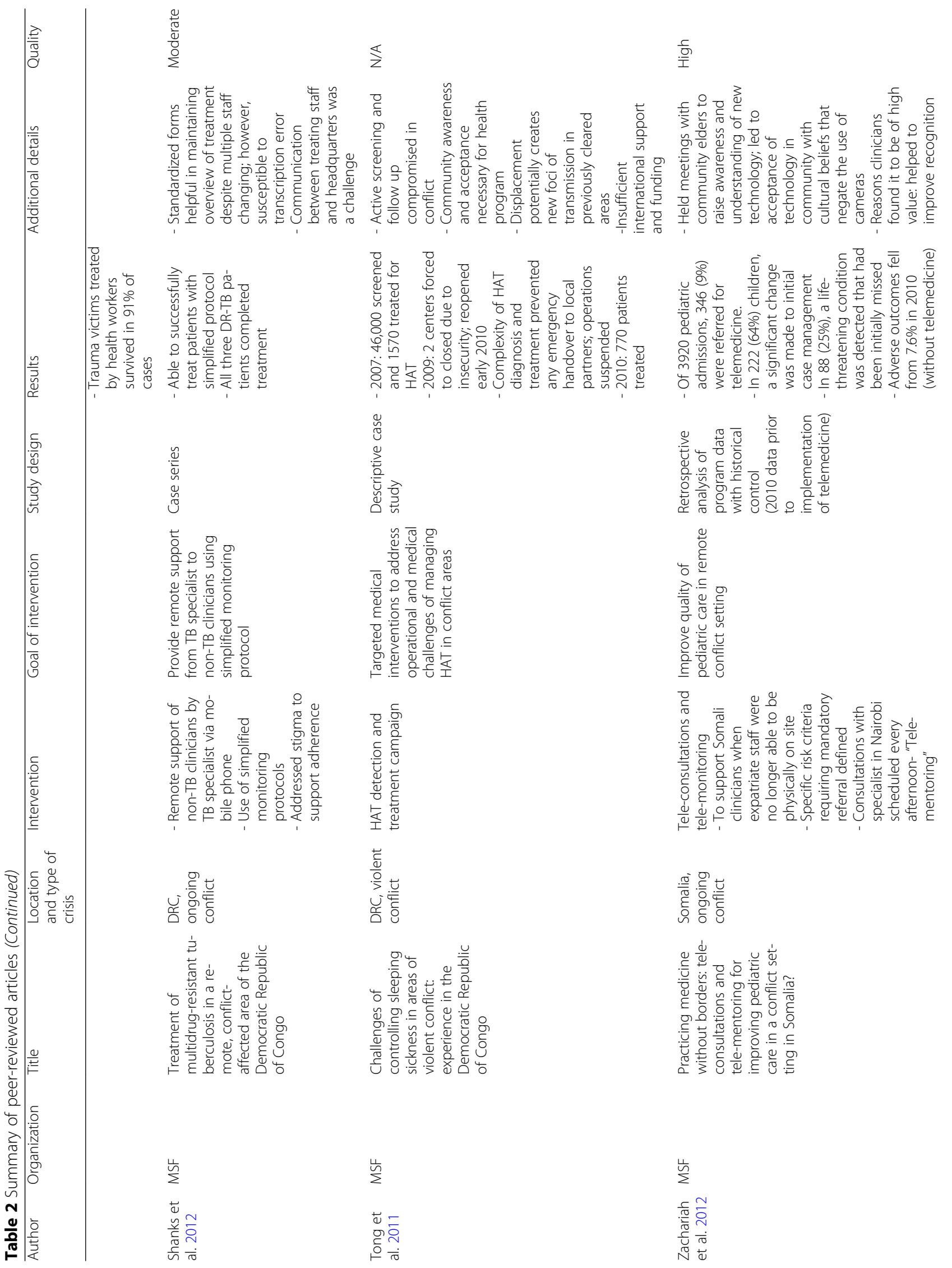




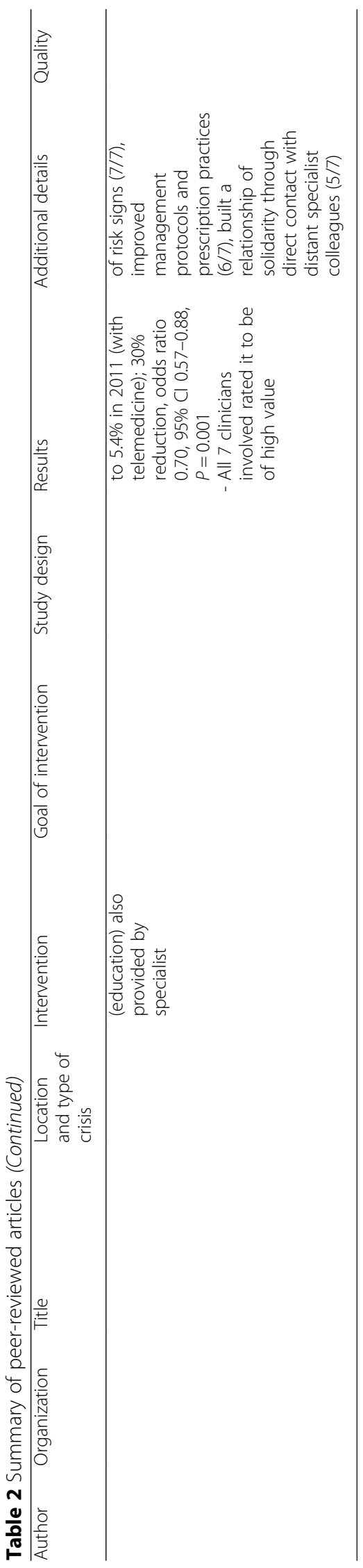


and flow of funding. It allows the retention of local knowledge, making it easier to return to traditional programming when access is restored, and provides opportunities for closer community involvement and local ownership. Remote operations increase the capacity of field staff, which contributes to sustainability. Additionally, the continued visibility of an organization will increase local acceptance of both current and future programming (Kjaerum 2015; Stoddard et al. 2006). Despite these benefits, programming and monitoring quality, neutrality, and impartiality tend to suffer with lack of international non-governmental organization (INGO) or international organization (IO) presence and all options for keeping staff on the ground should be considered prior to moving to remote operations as a last resort (Stoddard et al. 2006; UNHCR 2016). The potential benefits and challenges of shifting a program to remote mode require full consideration to inform the decision; challenges and considerations will be discussed in detail below.

\section{Traditional modalities of remote operations}

The literature identified four modalities of remote programming that exist on a spectrum, varying by depth of roles and responsibilities of both international and local staff. They are:

1. Remote control: commonly a reactive stance (action in response to a situation that has already occurred) and a last resort with the least amount of delegation of authority to field staff, and little capacity development or skills transfer (GOAL 2016; Hansen 2008b; Zyck 2012).

2. Remote management: a reactive stance with some delegation of authority to national implementers, moderate investment in capacity building, and procedures in place for better monitoring and quality. Assumes that decision-making and authority will revert back to internationals following restoration of security (GOAL 2016; Hansen 2008b; Zyck 2012).

3. Remote support: a proactive strategy (action in preparation for a situation that has yet to take place) with full investment in national staff capacity building, mentoring, and planning for eventual full handover of authority (GOAL 2016; Hansen 2008b; Zyck 2012).

4. Remote partnership: a proactive strategy where equal partnership is fostered with a local partner that already has significant internal capacity, and therefore does not require capacity development support from the international organization. The international organization supports via administration, resource mobilization, and advocacy, while the operational partner focuses on context and implementation (GOAL 2016; Hansen 2008b; Oxfam International and Merlin 2009; Zyck 2012).

A summary of remote operation modalities is presented in Table 3. This table is a synthesis of the resources cited and describes trends and qualities in relation to the other modalities; the descriptions are not intended to be absolute. The modality chosen for a specific operation will be based not only on desired characteristics (such as flexibility, quality, or sustainability) but will also be constrained by available resources and collaborations.

\section{Other remote approaches}

Other remote approaches include community partnership arrangements, government partnership arrangements, and outsourcing to commercial contractors; however, no reports analyzed their implementation in detail, preventing their inclusion in Table 3.

\section{Remote operations challenges, considerations, and approaches}

Analysis of the studies identified a number of factors that must be considered when implementing remote operations, including the need to maintain humanitarian principles; the selection and capacity of, and the communication, trust, and sustainability within partnerships; coordination and collaboration among stakeholders; acceptance of the intervention by both implementers and beneficiaries; risks and risk management, especially those associated with local actors; advocacy; monitoring and evaluation methods and technological support; preventing the "remote operations trap"; and the need for planning and guidance. These will be discussed in turn below.

\section{Need to maintain humanitarian principles}

The humanitarian principles of humanity, neutrality, impartiality, and independence (OCHA 2012) are necessary to ensure the safety of staff and communities. However, they are difficult to maintain during remote operations. Many IOs give little consideration as to whether or not local partners seek to uphold these principles (Stoddard et al. 2006). Neutrality can be affected through partnering with military forces to deliver aid (Polio Oversight Board 2014; UNICEF EMOPS 2011c), while impartiality can be compromised by religious, ethnic, or political dynamics that put pressure on local staff (Belliveau 2013; Stoddard et al. 2010). One example of compromised humanitarian principles was the UNICEF operation in Afghanistan between 2007 and 2010. Military partners were relied upon to access southern 
Table 3 Summary of remote operation modalities (Hansen 2008b; Oxfam International and Merlin 2009; Stoddard et al. 2006; Zyck 2012)

\begin{tabular}{|c|c|c|c|c|}
\hline & Remote control & Remote management & Remote support & Remote partnership \\
\hline Nature & Reactive & Reactive & Proactive & Proactive \\
\hline International staff authority & High/complete & Moderate & Low & Low/none \\
\hline National staff authority & Low/none & Moderate & High & High/complete \\
\hline $\begin{array}{l}\text { National staff capacity } \\
\text { development }\end{array}$ & Little & Moderate & Full & Unnecessary \\
\hline Longitudinal monitoring & Little & Some & Full & Full \\
\hline Flexibility & Little & Some & Very & Very \\
\hline Quality & Low & Moderate & High & High \\
\hline Sustainability & Low & Moderate & High & High \\
\hline Time-line & Short term & Medium term & Long term & Long term \\
\hline \multirow[t]{2}{*}{ Vulnerable to staff turnover } & High & High & \multirow{2}{*}{$\begin{array}{l}\text { Low (investment in local } \\
\text { staff capacity development } \\
\text { limits turnover) }\end{array}$} & \multirow{2}{*}{$\begin{array}{l}\text { Low (highly developed } \\
\text { local organizations } \\
\text { limits turnover) }\end{array}$} \\
\hline & \multicolumn{2}{|c|}{$\begin{array}{l}\text { (Minimal local capacity development increases vulnerability to } \\
\text { turnover) }\end{array}$} & & \\
\hline $\begin{array}{l}\text { Required experience in } \\
\text { context and infrastructure } \\
\text { by local organization }\end{array}$ & Minimal & Some & Yes & Yes \\
\hline Potential benefits & $\begin{array}{l}\text { - Continuity of program } \\
\text { - Better initial oversight given } \\
\text { primarily controlled by } \\
\text { international organization }\end{array}$ & $\begin{array}{l}\text { - Continuity of program } \\
\text { - Better initial oversight given } \\
\text { primarily controlled by } \\
\text { international organization } \\
\text { - Capacity building }\end{array}$ & $\begin{array}{l}\text { - Continuation of program } \\
\text { long term, sustainable } \\
\text { - Tailored to changing } \\
\text { context }\end{array}$ & $\begin{array}{l}\text { - Continuation of } \\
\text { program long term, } \\
\text { sustainable } \\
\text { - Tailored to changing } \\
\text { context }\end{array}$ \\
\hline Potential weaknesses & $\begin{array}{l}\text { - Communication problems } \\
\text { - National staff bear much of } \\
\text { responsibility and risk with } \\
\text { little authority } \\
\text { - Unsustainable }\end{array}$ & $\begin{array}{l}\text { - Communication problems } \\
\text { - National staff bear much of } \\
\text { responsibility and risk with } \\
\text { little authority }\end{array}$ & $\begin{array}{l}\text { - Corruption risk } \\
\text { - Lack of oversight } \\
\text { - Scarcity of experienced } \\
\text { national staff }\end{array}$ & $\begin{array}{l}\text { - Corruption risk } \\
\text { - Lack of oversight } \\
\text { - Scarcity of } \\
\text { experienced national } \\
\text { staff } \\
\text { - Reduced funding due } \\
\text { to donor reluctance }\end{array}$ \\
\hline
\end{tabular}

provinces and meetings with populations and stakeholders were held in military-controlled Provincial Reconstruction Team facilities; while this was the most feasible option at the time, it severely compromised their stance as an impartial and neutral actor (UNICEF EMOPS 2011a). Ensuring national and local staff have a sound understanding of humanitarian principles is necessary for programming and monitoring to be delivered in keeping with global standards (Egeland et al. 2011).

Some discussion posits that while impartiality and neutrality are important in these contexts, the core principle that deserves emphasis is the humanitarian imperative: the need to get critical assistance to those in need regardless of the method. This argument implies that a "by any means necessary" approach should be favored over attempts to maintain humanitarian principles in these settings (Stoddard et al. 2010).

\section{Partnerships}

Several studies described the necessity of effective partnerships supported by clearly delineated responsibilities, a defined supervision structure with a variety of focal points, and transparent policies that allow all parties to make informed choices and adequately fulfill their roles (IMC 2016b; Stoddard et al. 2006). Four sub-themes emerged throughout the partnership discussion, these are selection, capacity, communication and trust, and sustainability.

Selection Selecting a suitable partner to implement remote operations requires protocols and checks in place to ensure partners have sufficient capacity and experience in the context, and are not influenced by alternate agendas (Stoddard et al. 2010). Hiring third party accounting firms, deferring to community elders, and identification through contacts have all been described as potential partner selection methods (Howe et al. 2015). Ultimately, selection must be transparent and benefits from more active recruitment methods such as consulting local experts and utilizing pre-conflict networks (UNICEF EMOPS 2011b).

Capacity Several studies consider building the capacity of local staff important to ensuring the fidelity of remote 
operations, autonomy, and project ownership. While training needs (operational methods, security protocols, etc.) and methods (planned site visits, staff secondments, etc.) are varied and complex, these studies emphasize that training should be prioritized before remote operations take effect, acknowledge cultural and linguistic differences, and include follow-up and feedback to ensure retention and continuous improvement (GOAL 2016; Jansury et al. 2015; Stoddard et al. 2010). National staff can be experienced, and assuming all nationals require training can create an unequal relationship and should be avoided (Collinson and Duffield 2013). While capacity building is important, it is a long-term goal that can also lead to a short-term loss in efficiency; this trade-off requires consideration and needs to be evaluated against the urgency and needs of the context (UNICEF EMOPS 2012).

Communication and trust Building trust is considered key for partnerships and intrinsically linked to communication, a crucial trust-building strategy when working remotely; useful trust building mechanisms include maximizing face-to-face contact, regular sharing of ideas and information, enhanced interactions (for example, videoconferencing), transparent decision making, and joint agenda setting, among others (Anonymous 2015; Balslev-Olesen and Hüls 2011; GOAL 2016; Howe et al. 2015; Norman 2012). Communication strategies should specify the frequency, mode, and type of information to be shared (GOAL 2016). A minimum level of face-to-face contact between senior staff and implementers is required to build trust and capacity.

Sustainability Sustainability is a growing concern where national staff is relied upon to deliver services for increasing lengths of time. Prioritizing the sustainability of local partners involves focusing on operational and organizational capacity building of entire institutions, supporting long-term projects, providing core funds, and supporting alliances among local groups, thereby building a strong civil society (Howe et al. 2015). Sustainability is also supported by rapid decentralization to skilled staff and flexibility in rapidly changing contexts, versus hierarchical management structures and procedures (Hansen 2008b).

A 2006 dissertation paper that examined cases in a number of countries highlighted both the advantages and disadvantages of partnerships that relied on communities to implement projects in Uganda. An anonymous NGO developed program activities and implementation time lines with community representatives in a neighboring town. Community members implemented the program (with some private contractors) and documented implementation using field journals and digital photographs. The NGO supported the community implementers with supplies, training, and regular guidance and feedback following review of documentation. The community was aware that the NGO would be monitoring activities, and independent monitors from the communities were recruited to triangulate information. A change in the security situation, which permitted the NGO to visit the project area with government escorts, found that this monitoring system was unreliable. Work was of poor quality and in some cases not carried out at all, despite payments being made and verification of the work by the NGO's national staff. Community members were found to be providing information that they thought the NGO wanted to hear, instead of reporting on the realities on the ground (Rogers 2006).

\section{Coordination and collaboration}

Coordination and collaboration are considered essential to ensuring cohesive remote programming; however, certain coordination structures can also compromise an organization's independence and capacity. Structures should be rooted in the cultural context, with coordinating bodies and leadership carefully selected to promote neutrality and local ownership (Stoddard et al. 2010). There is a need for coordination mechanisms and standards to be adapted to the realities of operating in conflict contexts, and to improve the efficacy of the cluster approach for remote programming (UNICEF EMOPS 2011a). Good practices exist, but are generally confined within an organization and need to be shared (Norman 2012).

One example of effective coordination is the shura (council) system in Afghanistan developed by Tearfund to mimic the local decision-making structure based around group consultation. Following insecurity that forced coordination activities to relocate from Kandahar to Kabul, the lack of an expatriate program manager was feared to unleash tribal differences among Afghan staff members. In an attempt to preempt these tensions from causing problems, a shura was developed with the five program heads from the Kandahar office, each taking turns to coordinate the shura; all other staff members were invited to participate in deliberations as well. The inclusiveness to all opinions and lack of one controlling member helped to manage conflict and tensions between staff and prevented fraud or corruption as all members worked together and monitored each other. While this process was slow to develop and resulted in slow decision making initially, it was important given the cultural context and demonstrated respect for local governance mechanisms. The shura system led to programming that was highly accepted by the community, well-coordinated, and fairly implemented, while building sustainable local capacity and ownership (Souness 2011; Stoddard et al. 2010; UNHCR 2014; Zyck 2012). 


\section{Acceptance}

Acceptance is important to ensure the fidelity, execution, and uptake of remote operations; activities need to be accepted by both the national/local staff implementing them and the communities they aim to serve, with program ownership strongly linked to program success (Belliveau 2013). Acceptance is both a security measure and used to eventually regain access (Souness 2011; Steets et al. 2012). However, it should never be solely relied upon to reduce security risk.

Regular contact and participatory management styles that include national staff in decision making increase trust and acceptance by local staff, while selecting culturally appropriate staff, using diaspora nationals, and community outreach and participation increase beneficiary acceptance (Oxfam International 2007; Rogers 2006; Stoddard et al. 2006). The fundamental prerequisite to acceptance is competent and committed humanitarian programming with tangible results (Egeland et al. 2011).

\section{Risks and risk management}

Risks to local actors Remote operations involve the transfer of risk from international to local actors, who are assumed to be at lower risk for targeting and therefore safer when implementing (GOAL 2016; Hüls 2011). This is often a false assumption as they face unique threats that are often not acknowledged in security assessments (Egeland et al. 2011) and may accept a greater degree of risk than is deemed appropriate (Stoddard et al. 2006). Additionally, local actors are infrequently present at trainings on security, and are often left with minimal security-related equipment when expatriates evacuate (Collinson and Duffield 2013).

Mitigation of this risk can be achieved via conducting thorough risk assessments (GOAL 2016; UNHCR 2016), preparedness planning that decentralizes authority and transfers security equipment to nationals (Stoddard et al. 2006), (Schreter and Harmer 2013), capacity building on security issues and protocols, and additional monitoring and triangulation with community members for risk updates (GOAL 2016; Norman 2011; Stoddard et al. 2010).

General risks General risks in remote operations are many and include inadequate and poor quality information management, credibility, communication, coordination, monitoring, and programming; inciting conflict; casualties and fatalities; insufficient impact; limited or no program expansion or adaptation; compromised neutrality and impartiality; corruption and fund diversion; and reduced advocacy or speaking out on behalf of affected populations (Belliveau 2013; Rivas 2015; Stoddard et al. 2006; Stoddard et al. 2010). Risks can also vary depending on which staff are removed from the program; removal of only expatriate staff may expose them to higher risks when visiting, and may expose national staff to higher risks when they are absent, due to lack of security infrastructure. Removal of nearly all staff may be more acceptable but can reduce program quality and place more risk on the beneficiary when accessing assistance (Stoddard et al. 2006). These risks are exacerbated by inadequate risk perception and a decreased sense of urgency from remote managers who lose touch with the situation on the ground (Cunningham 2016; GOAL 2016). Policies need to be implemented that acknowledge the realities of fraud and corruption on the ground.

General strategies for reducing risk include building strong relationships with communities, strategic coordination with partners, and detailed monitoring, among others (GOAL 2016; UNICEF n.d.). Additionally, donor and organizational reporting requirements need to ensure they do not put national staff at increased risk and clear contingency plans are required prior to deterioration in security in order to maximize risk management (Howe et al. 2015; UNICEF EMOPS 2012).

\section{Advocacy}

Advocacy is thought to suffer in remote operations, as it is highly dependent on the presence of international staff. The legitimacy of the message is directly related to presence in the field, and cannot be substituted by that of local NGOs (LNGOs), who usually do not have the same influence as their international counterparts. Remote operations were found to weaken protection activities in Afghanistan that were dependent on advocacy from INGO/IOs (Stoddard et al. 2010). Communication and advocacy efforts are also critical to the re-enforcement of community ownership and program acceptance, thus despite the restrictions, they should be increased when shifting to remote operations (UNICEF EMOPS 2011a). UNICEF Iraq found that implementing partners could be used to deliver messages on the ground. However, policy and decision messaging had to come from UNICEF directly to be effective (UNICEF EMOPS 2011b).

\section{Monitoring and evaluation}

Accountability in remote operations is multifaceted and includes both upward accountability to donors and downward accountability to beneficiaries. It is a crucial component of risk mitigation and management, with increased monitoring and reporting requirements than traditional programming due to the lack of field presence and direct oversight by INGO/IOs. Accountability is further compromised by limited opportunities for data collection, poor quality data and inaccurate information, 
lack of monitoring skills and capacity of local staff, lack of good baseline data for performance indicators, issues with safely sharing information, rapid aid influxes that necessitate immediate action and prevent monitoring and evaluation (M\&E) from being built in at the onset, and difficulty gaining support from local staff who may feel money is better spent on delivery of aid (Jansury et al. 2015; Norman 2011, 2012; Rivas 2015; Souness 2011; Zyck 2012). One study found that only 8 out of the 20 INGO/IOs interviewed had an organizational M\&E framework (Norman 2011).

Upward accountability Upward accountability to donors is the focus of the majority of monitoring activities (Stoddard et al. 2010). However, donor expectations are often not well-suited to fragile settings, can increase risk to local partners (Howe et al. 2015), and can detract needed funds from programming; increased flexibility and realism is required (Rivas 2015; UNICEF EMOPS 2011a).

Downward accountability Downward accountability to beneficiaries ensures target population needs are being met and aid is delivered equitably and as intended. However, it is often forgotten by organizations (Faubert et al. 2010; GOAL 2016). Methods for monitoring of downward accountability include beneficiary rapid assessment surveys (IOM 2008), feedback forms (GOAL 2016; Oxfam International 2007; Rivas 2015), hotlines (UNHCR 2014), meetings and discussions with communities (Rivas 2015; Souness 2011), systems of complaints redress (GOAL 2016; Norman 2012; Stoddard et al. 2010), structures that promote beneficiary participation (Norman 2012), and prioritizing beneficiary accountability within senior management (Kjaerum 2015).

General methods A clear plan for M\&E must be designed; monitoring in remote operations may need to be more intensive and can require significant resources and tools beyond those used in direct management settings (GOAL 2016). Several general methods exist to support internal and external M\&E initiatives in remote operations; internal M\&E is considered less rigorous than external due to reduced transparency, neutrality, objectivity, and impartiality (Jansury et al. 2015).

Internal monitoring methods include having clear monitoring and reporting structures delineated in advance (CDC 2016; GOAL 2016; Stoddard et al. 2010), specific monitoring capacity within an organization, and regular communication, written reports, and strict deadlines for field staff (Rogers 2006; Stoddard et al. 2010). External monitoring methods include contracting local firms for independent third party monitoring (Balslev-Olesen and Hüls 2011; Egeland et al. 2011; IOM 2008;
Rivas 2015; Stoddard et al. 2010; UNICEF 2016; UNICEF EMOPS 2011b), cross checking information with field and community contacts (Balslev-Olesen and Hüls 2011; ECHO 2013; Egeland et al. 2011; GOAL 2016; Schreter and Harmer 2013; Stoddard et al. 2010; UNICEF 2016), and sharing monitoring capacity with other organizations (UNICEF EMOPS 2012).

Technological support Technology has been employed in a variety of facets to enable electronic or web-based monitoring (Balslev-Olesen and Hüls 2011; GOAL 2016; Howe et al. 2015; Schreter and Harmer 2013; UNICEF EMOPS 2012). Examples include mobile phone monitoring applications, satellite imagery, barcode tracking systems, and mapping software, among others. Further research and investment in data collection and analysis, and communications technology is required with the aim of streamlining its incorporation across programs.

Save the Children Somalia experimented with simulated technical field visits to provide support to their nutrition operations in Hiran, Somalia; the first visit was completed over Skype in October 2015. The objectives were to monitor the nutrition programs and verify their existence, assess quality against benchmarks, identify gaps and areas for capacity development, and motivate the field teams via establishing rapport. Standards and benchmarks were agreed upon and the field team provided electronic evidence (scanned patient cards and stock records, focus group discussion notes, completed checklists, photographs, etc.) for the international staff to review prior to the call. The call then allowed for a joint review of the documents with the field, provision of feedback, and development of an action plan. A recent simulated field visit found that the mean upper arm circumference measurement was performed incorrectly and outpatient cards were improperly filled out, indicating further training was required. They were also able to assess the site via photographs, noting the buildings did not provide a shaded waiting area for mothers and lacked adequate furniture. The lessons learned from this process include prior preparation and extensive communication is required to ensure a complete set of documents is delivered for assessment, taking representative photographs is a skill that must be taught, quality checklists were very useful, and strict discipline was required to set aside uninterrupted time to complete the visit. However, the utility of this process remains in question given the limited control over what the team chooses to present (Zikusooka et al. 2015).

\section{The "remote operations trap"}

The "remote operations trap" 1 refers to the inability to transition back to a traditional management mode after a program has been implemented remotely for some 
time (ECHO 2015; Stoddard et al. 2010). This is caused by a number of factors and effects including reduced ground-level information, less credibility of the agency, and increased risk for local partners. One NGO reported that after a year of programming remotely in Somalia, national staff became identified as decision makers and resource handlers and threats against them increased (Stoddard et al. 2009); this made it more difficult for them to reengage later by traditional means. Additional contributors to the resistance to returning to regular operating mechanisms are the potentially outdated perception of dangerous areas and risk secondary to a loss of familiarity with the operating environment, a protection-oriented security culture, security costs allocating resources away from more comprehensive programming, and bureaucratic inertia (Kjaerum 2015; Stoddard et al. 2010). The best way to avoid the remote management trap is continuous reassessment and a pre-planned exit strategy.

\section{Planning and guidance}

There is a significant need for proactive planning and guidance on when to employ remote methods, how to operate effectively remotely, and when to exit remote operations. While considering the potential need for remote operations early in every program would be ideal, most agencies lack specific criteria to assess risk and guide these transitions (including an exit strategy) (Stoddard et al. 2006), plans for potential partnerships, and appropriate situation specific risk transfer practices to support decision making (Collinson and Duffield 2013), resulting in them often being used as a last resort. Guidance should cover all these topics, include indicators and checklists, and be integrated into the initial program planning documents in order to promote considered phasing into and out of remote operations (IMC 2016b; Steets et al. 2012; UNHCR 2016; UNICEF EMOPS 2011c). When original remote operation guidance has not been produced, adapting protocols to the new context must be prioritized; it should not be assumed that strategies outlined for regular operations would be appropriate in an inaccessible conflict setting (Zyck 2012). It is up to donors to provide flexible funding that is able to adapt to changes in implementation secondary to insecurity (Oxfam International 2007).

\section{Discussion}

The descriptive nature of the literature and the focus on defining concepts highlights that this field is in a relatively nascent stage. This review provides conceptual background and definitions that will aid in future discussions of remote operations using a common understanding and language. The themes identified in this review are consistent with those of other reviews and critical reports (Donini and Maxwell 2013; Kalkman 2018). The information in this review provides a foundation of examples of and lessons learned from experiences with remote operations in conflict-affected areas. This review is distinct from other review articles on remote operations (Donini and Maxwell 2013; Rivas 2015) as it employed robust systematic review methods and performed an extensive search of both peer-reviewed and gray literature. Together, this approach gathered a vast collection of experiences, methods, tools, and lessons learned from a variety of organizations, resulting in findings and conclusions that aim to limit bias and have broad relevance. The collection of tools that have been developed for remote programming and monitoring should also be helpful to other stakeholders as they work to develop their own tools.

The literature demonstrates that although many organizations are participating in remote programming or monitoring, few have documented their experiences so that lessons learned can be disseminated to other organizations or stakeholders. Of the documentation that exists, case studies were the predominant form of literature available; the lack of rigorous operational research measuring robust outcomes limits the ability to draw strong conclusions on the effectiveness of different approaches. The imbalance between peer-reviewed and gray literature sources demonstrates that while some organizations are documenting their work for internal review, despite their potential external utility, they face barriers in publishing these more experiential reports for a wider audience. More comprehensive tools, such as evidence-based best practice guidelines, remain difficult to create for a number of reasons, including the near impossible conditions that surround robust outcome data collection in insecure environments and the context-specific nature of many interventions that limits the ability to draw generalizable conclusions.

The nature of the remote operations model is wrought with difficult circumstances that demand frequent sacrifice, making the creation of and adherence to rigorous guidelines difficult. Despite this, there are a number of key principles that can be taken away from this review. The importance of capacity building and effective communication is crucial to develop trust between partners when working remotely. Capacity building and increasing partnerships with local staff have been found to be a benefit of remote operations but are also an essential component of risk mitigation in this setting (Donini and Maxwell 2013). The assumption that national staff are at a reduced risk is often false; the threats faced by national staff must be comprehensively assessed and addressed. This should be completed before the implementation of remote operations and ensure that national and local staff have a greater part in decision-making (Kalkman 
2018). M\&E methods must be reinforced and may require more intensity and resources than in direct management settings. And finally, planning remains crucial for all phases of remote operations, from creating contingency plans to support regular programs in the event a transition to remote operations is required, through to exit planning to guide the transition back to standard program methods and ensure they are not remotely managed for longer than necessary.

The movement toward the localization of humanitarian action supports the shift toward a more balanced humanitarian system where national and local actors are valued, supported, recognized, and reinforced by donors and INGOs. Remote operations have overlap with and can learn from localization principles and methods, such as prioritizing partnership management, supporting and strengthening the capacity of local and national organizations, and updating INGO policies and procedures to reinforce accountability, among others (Emmens and Clayton 2017).

\section{Limitations of the literature}

This review of gray and peer-reviewed literature on humanitarian health programming and monitoring in inaccessible conflict settings highlighted many themes and issues spanning multiple domains: humanitarian principles, partnerships, risks, advocacy, accountability, the "remote operations trap," and planning and guidance. While thorough in its analysis of content, one of the main limitations found throughout this review was that the literature focused on INGO/IO perspectives, with little information on the experiences of other players including national and local staff, religious and community-based organizations, and communities themselves. While remoteness from national and local partners is a defining characteristic of remote operations, their experience and perspective are invaluable and can greatly inform future guidelines and operations (Kalkman 2018).

The literature was also focused on service delivery and lessons learned but lacked detail on how interventions were implemented, what gaps need to be filled, and how they would have liked to do things differently, making it difficult to replicate these efforts and to think critically about which strategies were effective or how they could be improved. There is also limited discussion of the needs of the population or incorporation of a human rights framework, or of ethical issues other than risk transfer, such as confidential beneficiary data management, appropriate engagement strategies in high-risk environments, and the dissemination of monitoring data (Rivas 2015).

An additional limitation was the general lack of discussion on the costs of remote operations; specifically, what is sacrificed and lost when one is forced to program or monitor remotely. Only one peer-reviewed study reported on these drawbacks, citing limited coordination capacity resulting from reduced contact with local implementers (Mattli and Gasser 2008) and while it was mentioned in the gray literature, the responses were based more on observation than rigorous analysis. Further examination of the potential losses in program quality and fidelity are necessary to obtain a complete picture that can then be fully addressed; this cost-benefit analysis is an important avenue for future research in this field.

The majority of documents pertaining to this subject were neither published nor peer-reviewed and within the peer-reviewed literature, over one-third of the studies were case studies. This is consistent with other reviews which found most of the humanitarian evidence is from programmatic evaluations or reports, rather than peer-reviewed articles or academic studies (Krystalli 2017). Further, the majority of the documents found were descriptive in nature, with no quantitative assessments of the impact on program processes or health outcomes, demonstrating the difficulty of collecting high-quality data in remotely operated humanitarian emergencies. A major difficulty in conducting reviews of evidence from humanitarian settings is the convention of only including rigorous evidence-based studies and discounting studies that do not conform to these strict criteria (Krystalli 2017). Additionally, a lack of detail was prevalent throughout the literature, which was often attributed to organizations not wanting to discuss specific methods for fear of increasing security risk. In addition to the lack of rigorous research and evaluation of remote operations, there is an absence of guidelines or recommendations on best practices. Although some tools exist and are shared in this review, there do not seem to be any harmonized tools that reflect the variety of experiences or that have been vetted by the different agencies working in the field. As the evidence base for remote programming and monitoring is extremely limited, further information is needed on all aspects of this field of work (Donini and Maxwell 2013), including piloting and validating guidelines and tools and incorporating areas of operational research from the onset of remote programming and monitoring activities (Table 4).

\section{Limitations of this study}

A limitation of this review is the focus on remote programming and monitoring for health-specific interventions. While there are many principles and findings that can apply to other types of humanitarian interventions, generalizability remains restricted. 


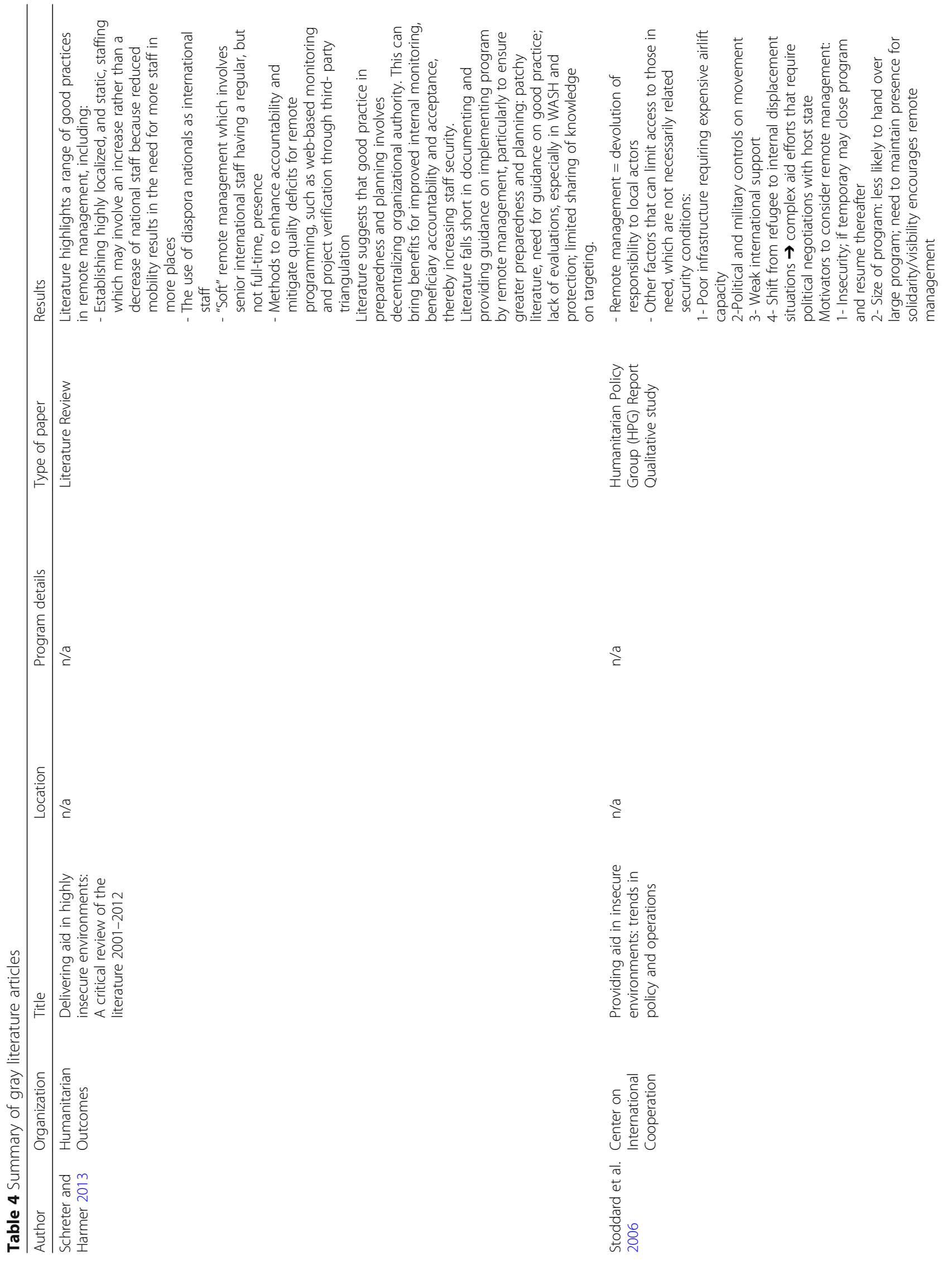




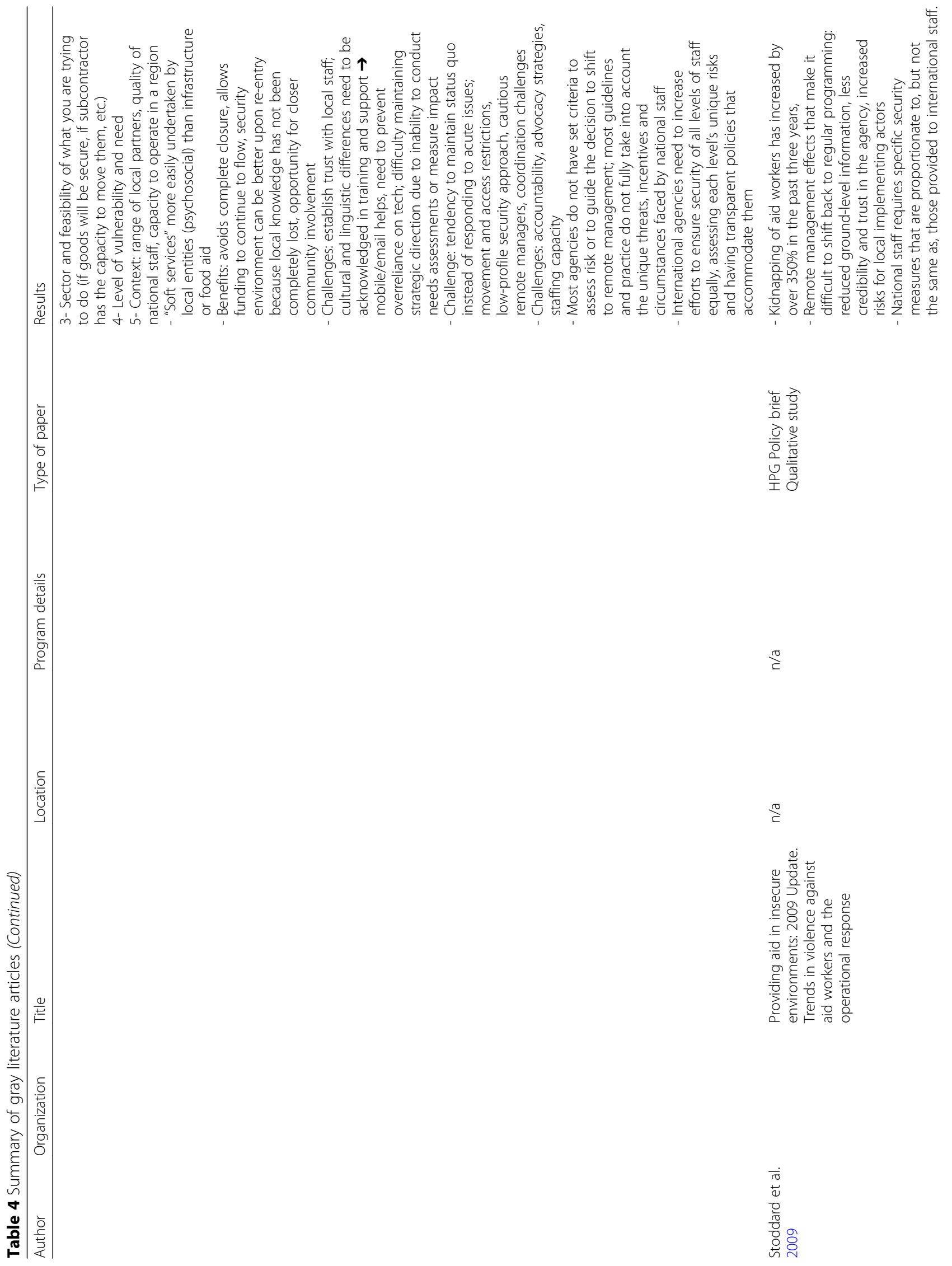



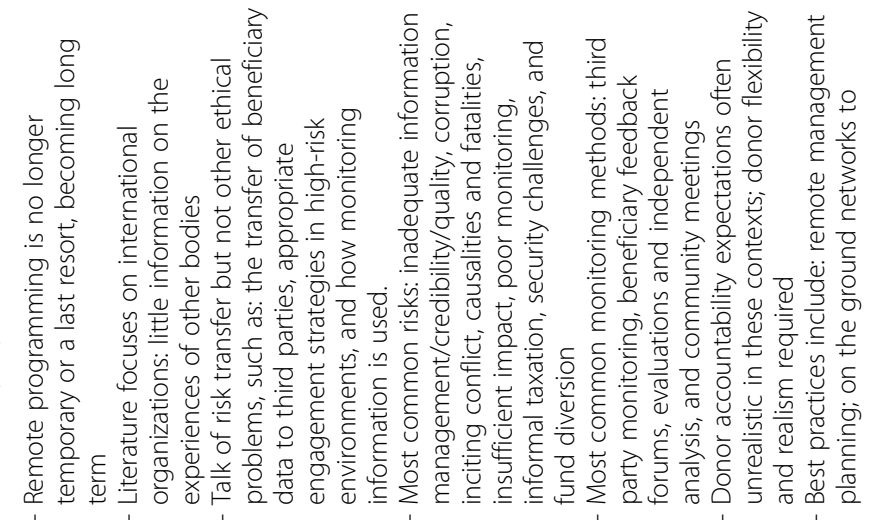

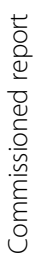

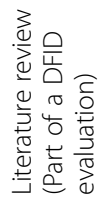

$\stackrel{0}{\Sigma}$

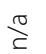

$\stackrel{2}{\check{c}}$

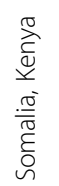
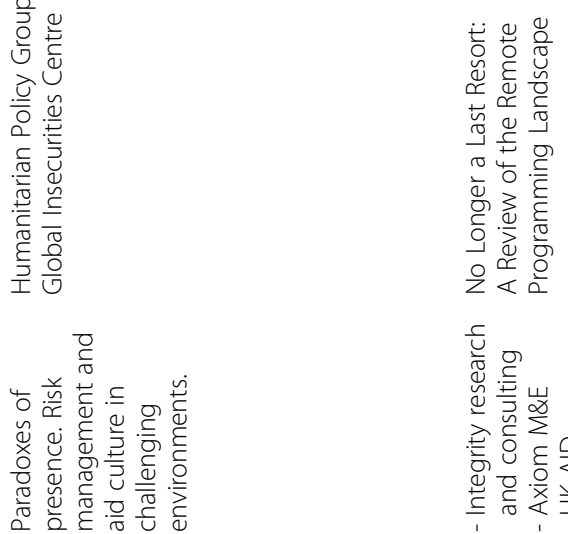

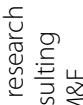

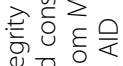

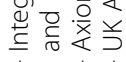

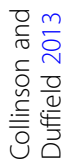

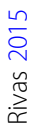




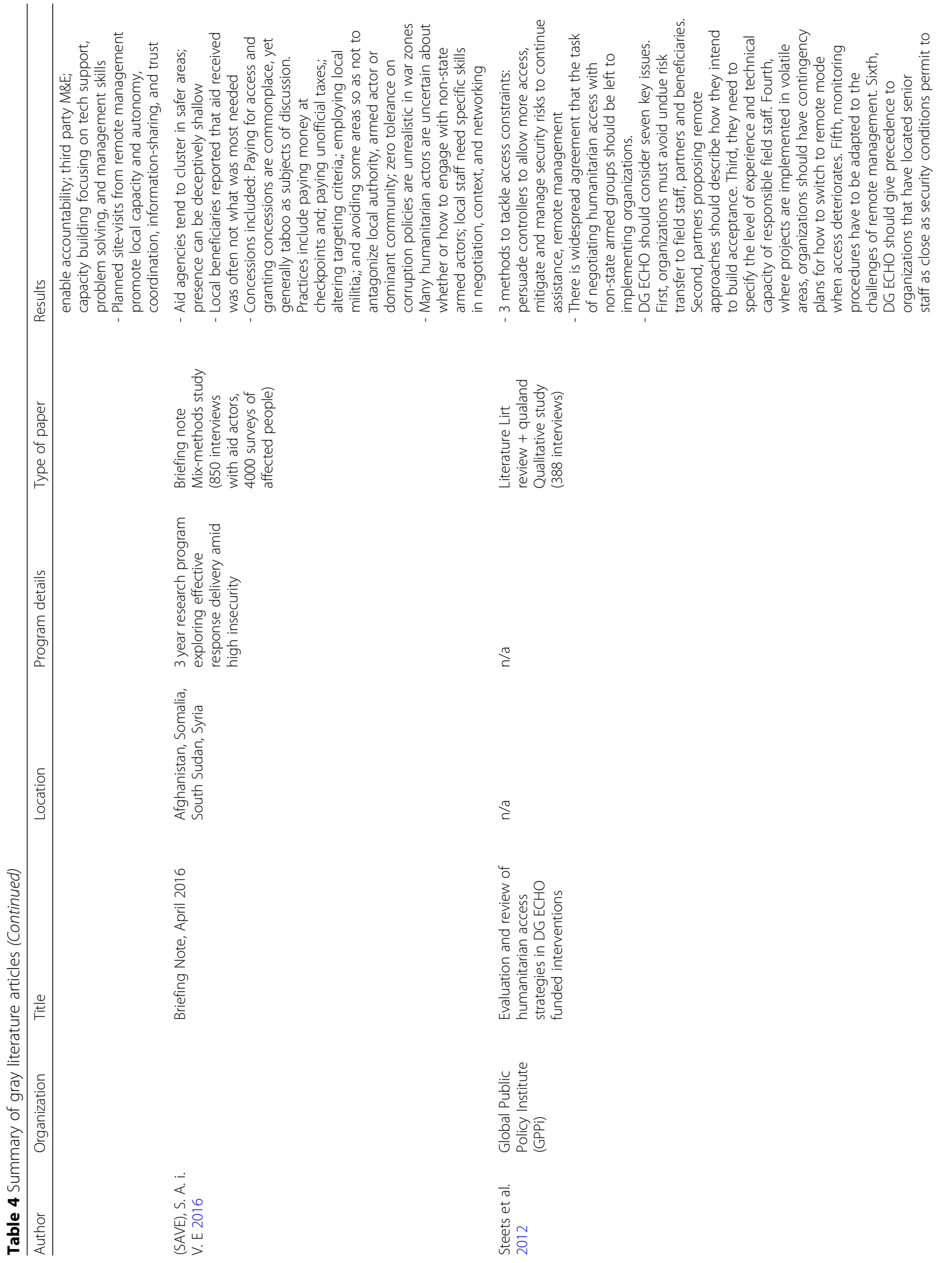




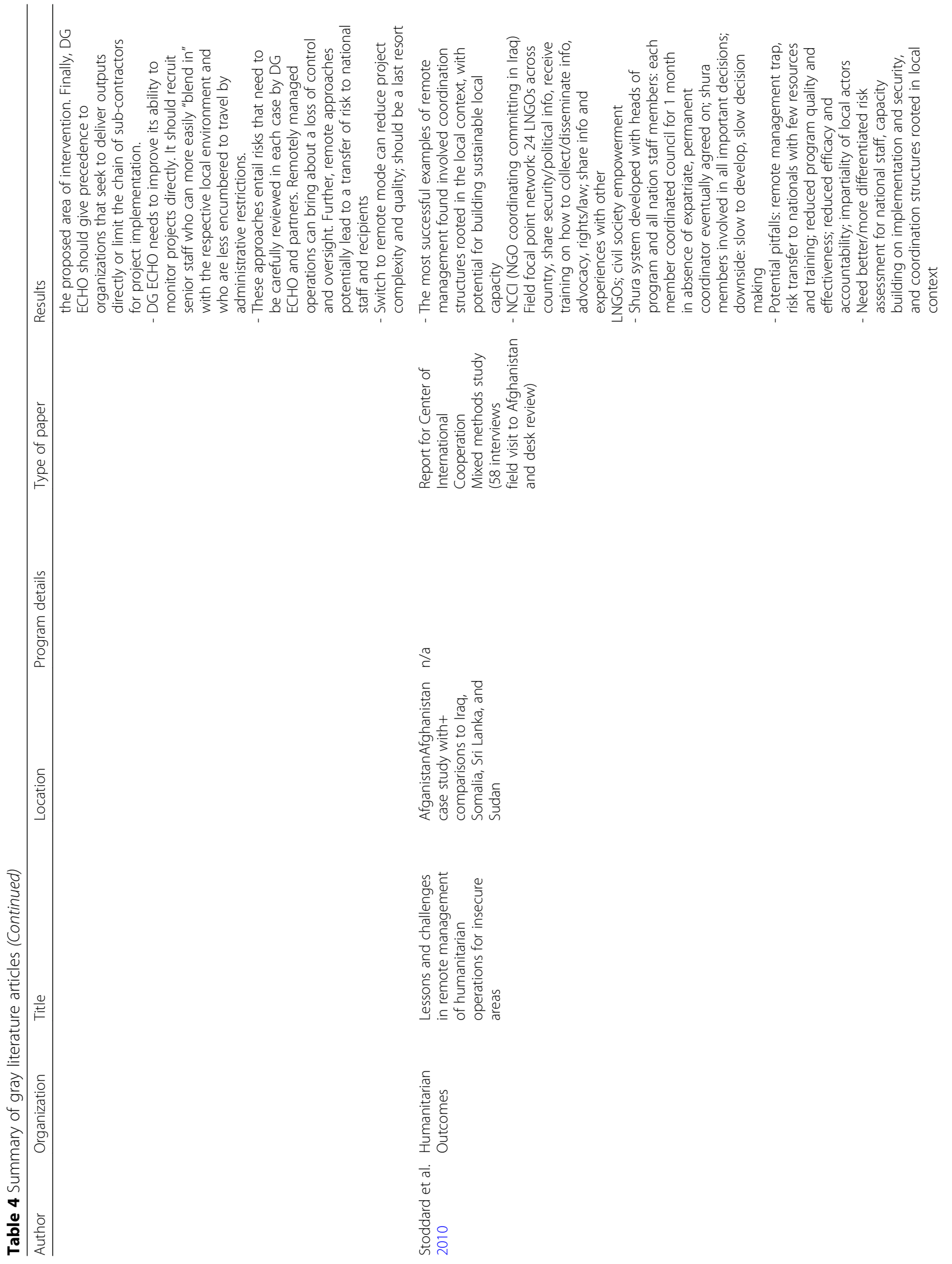




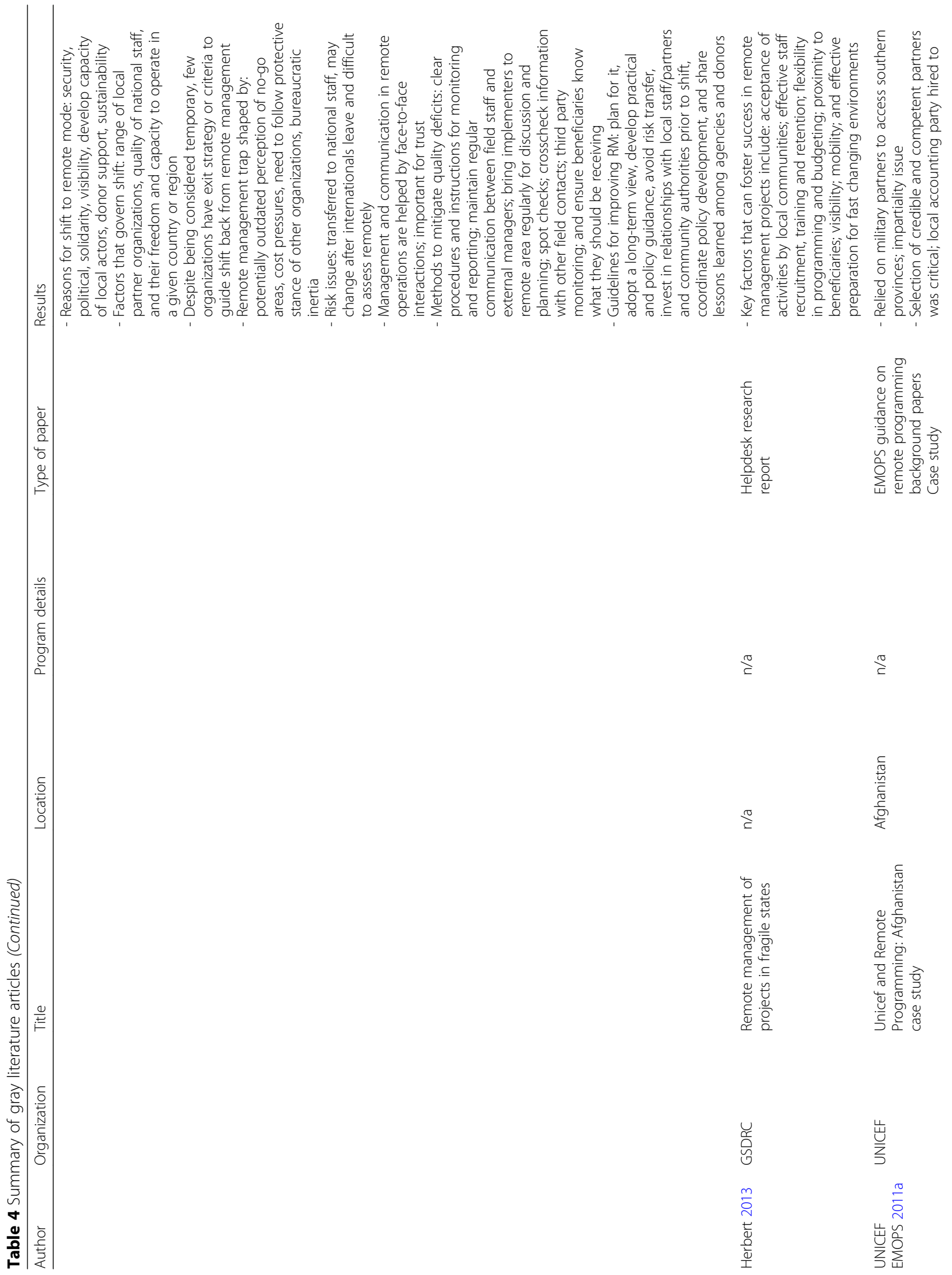




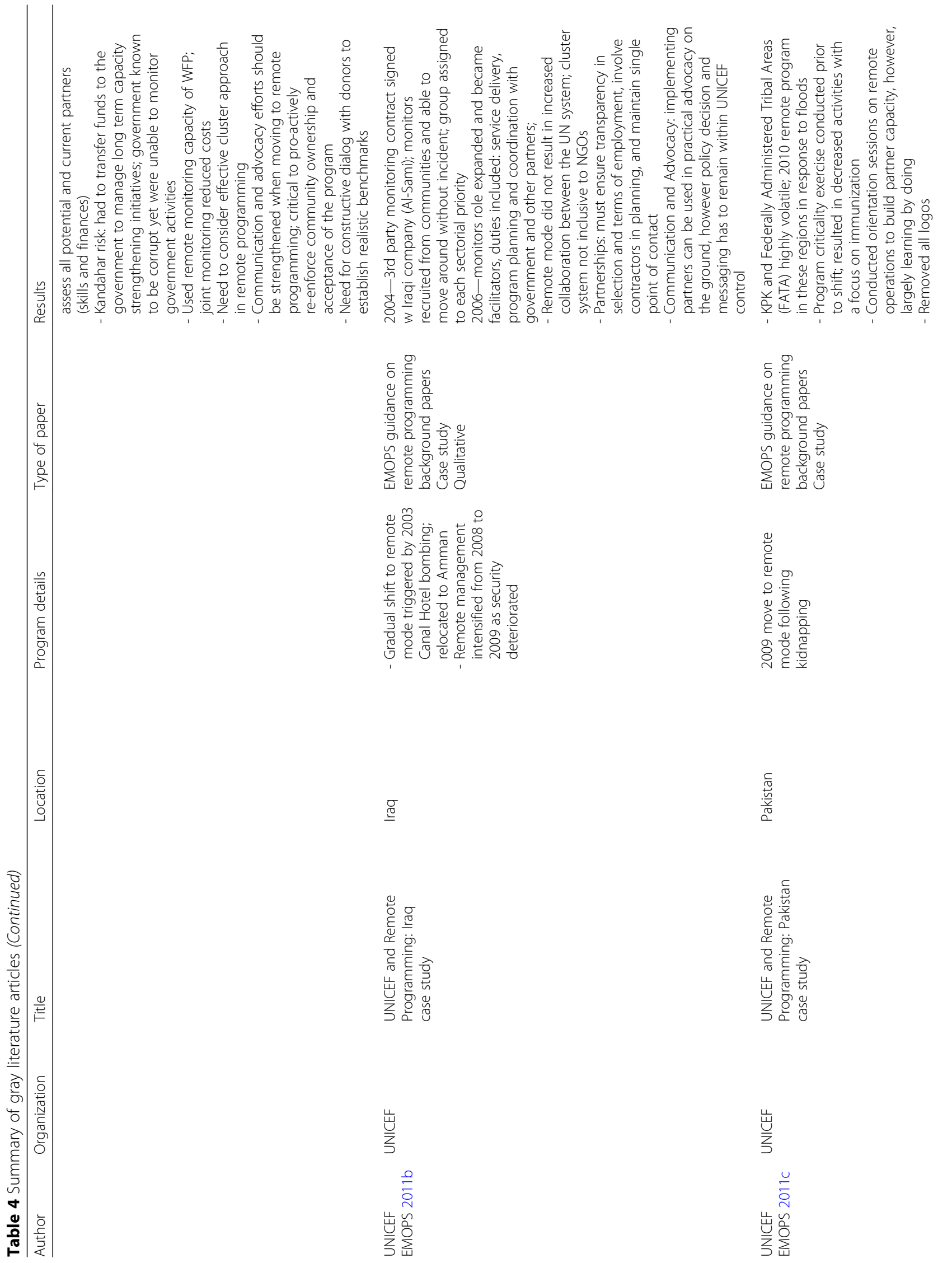




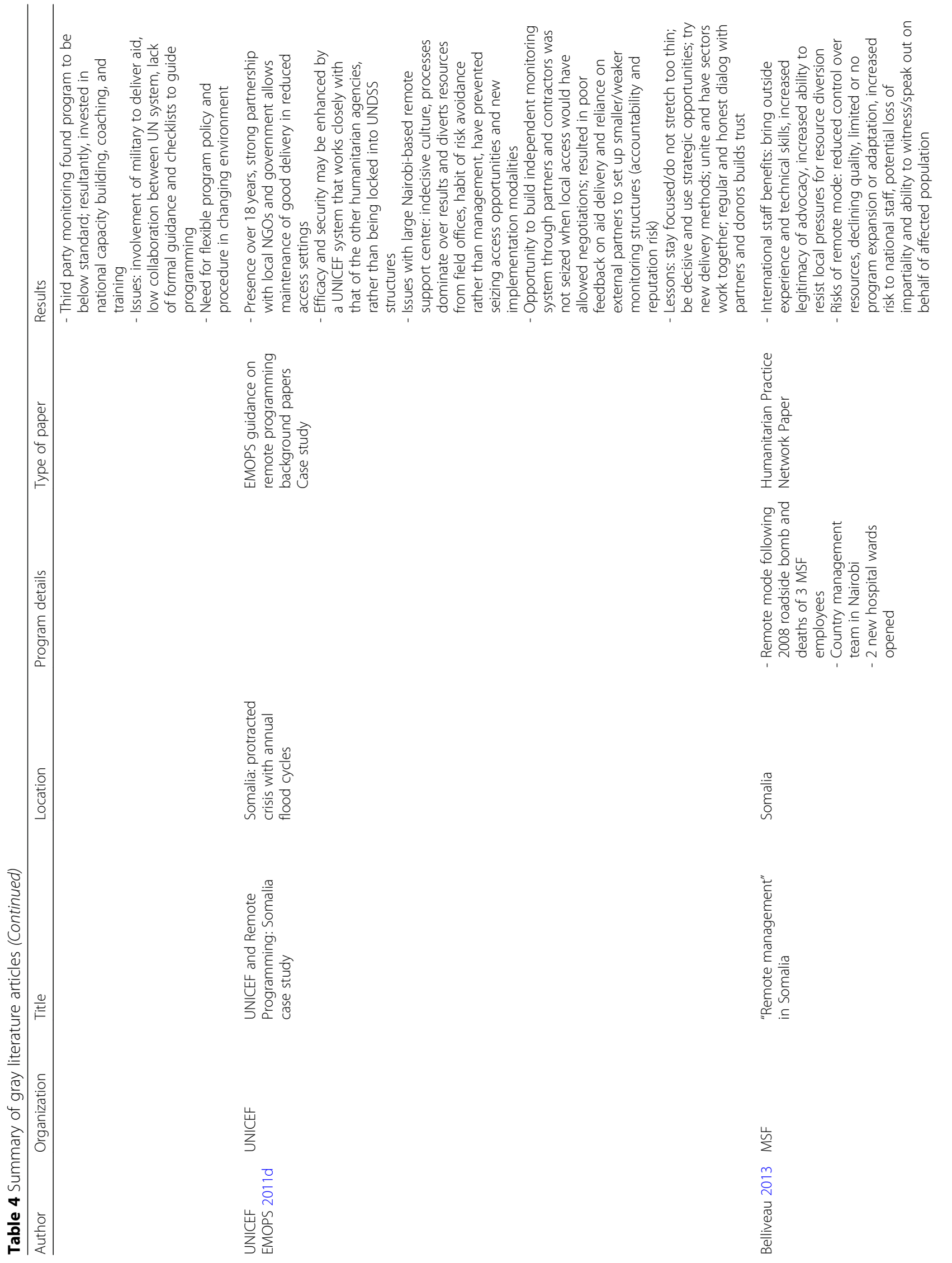




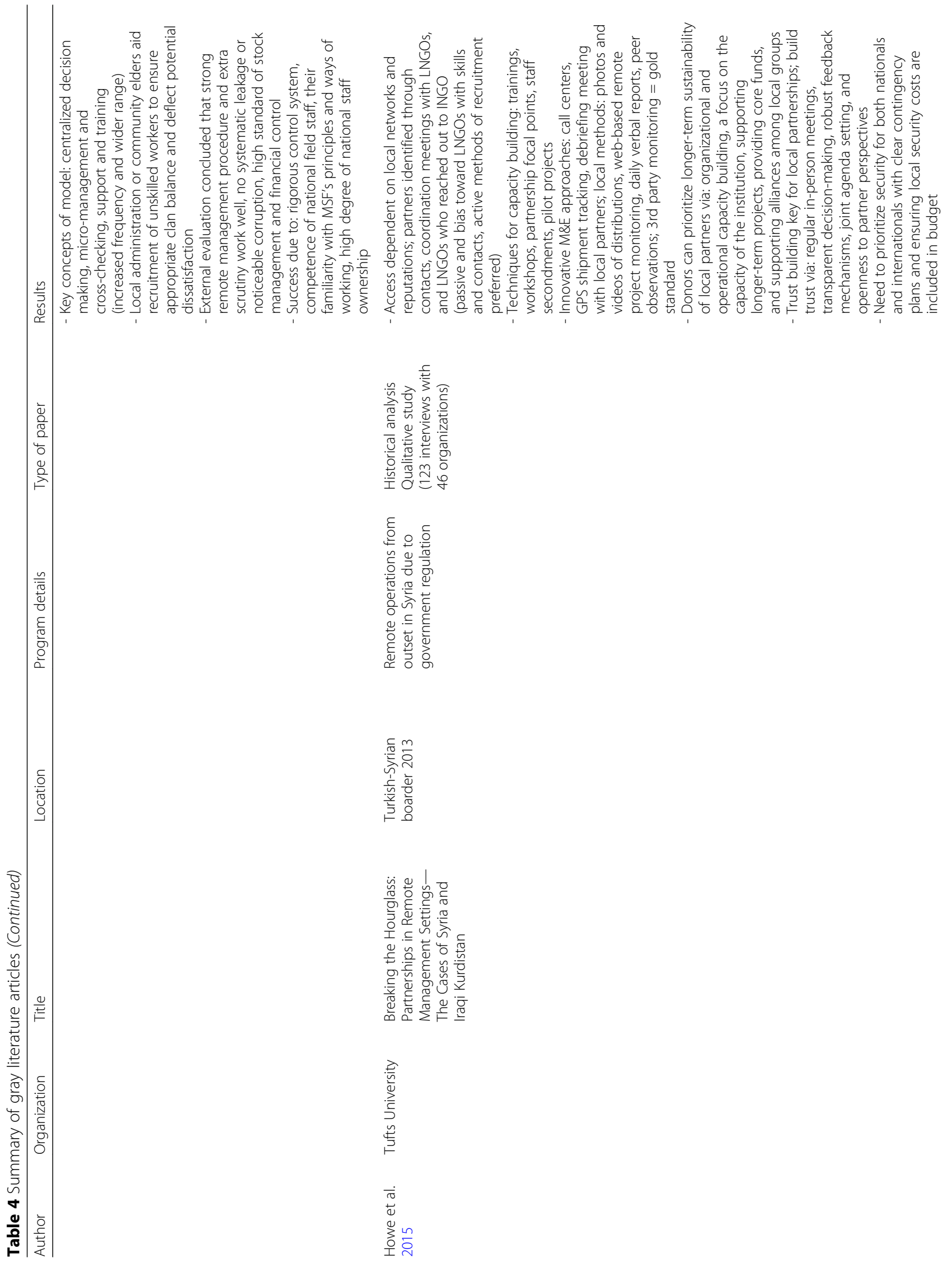




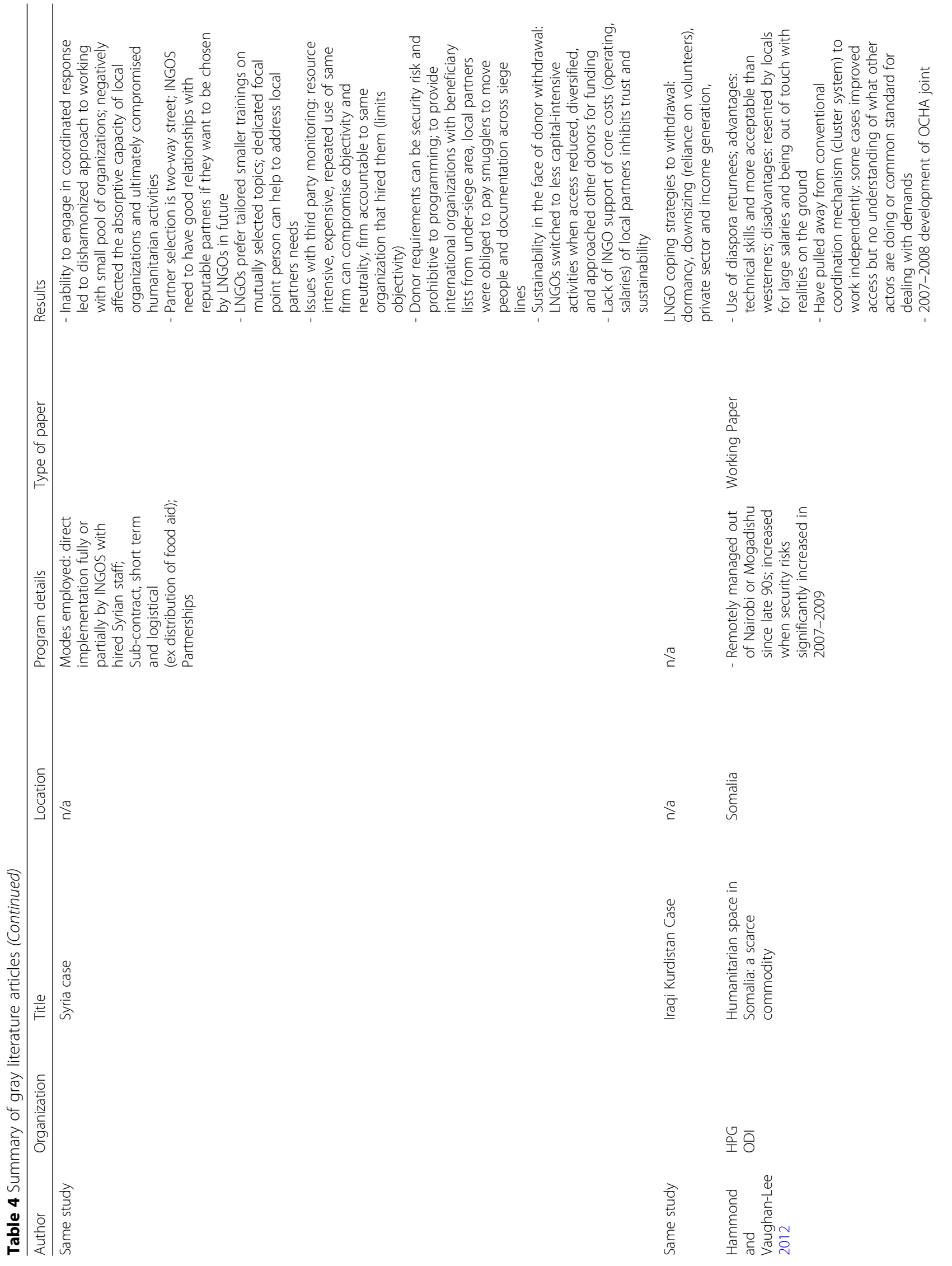




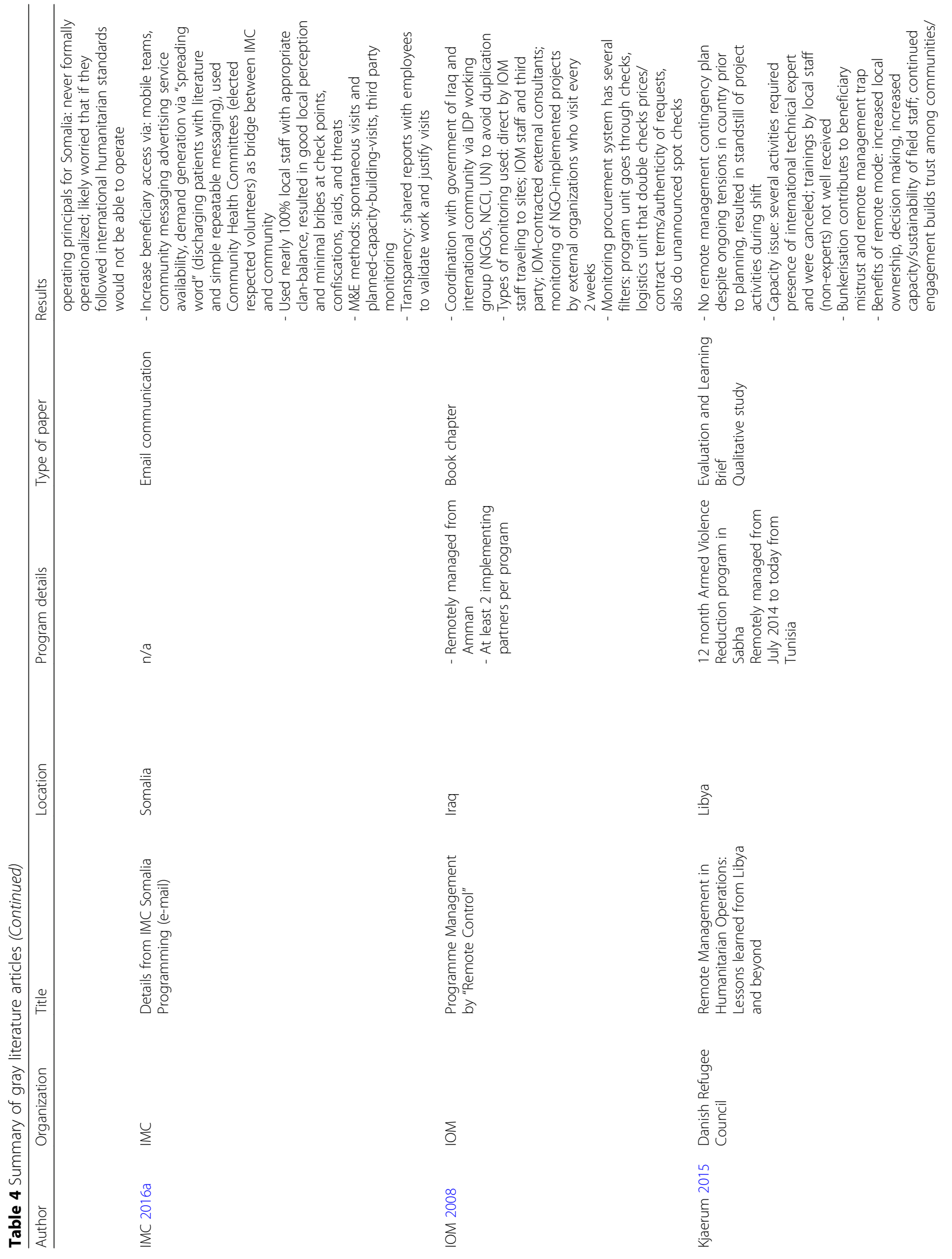




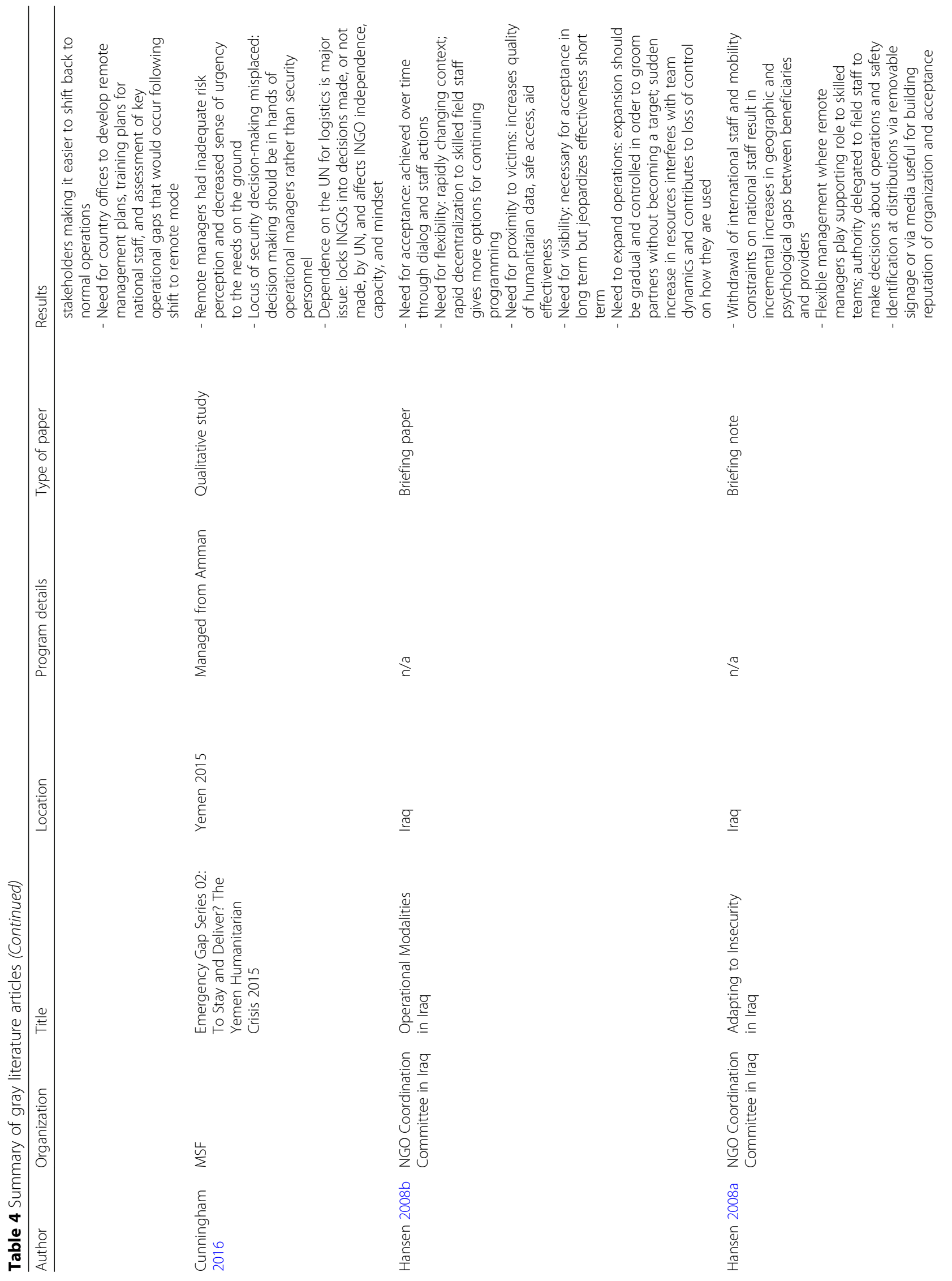




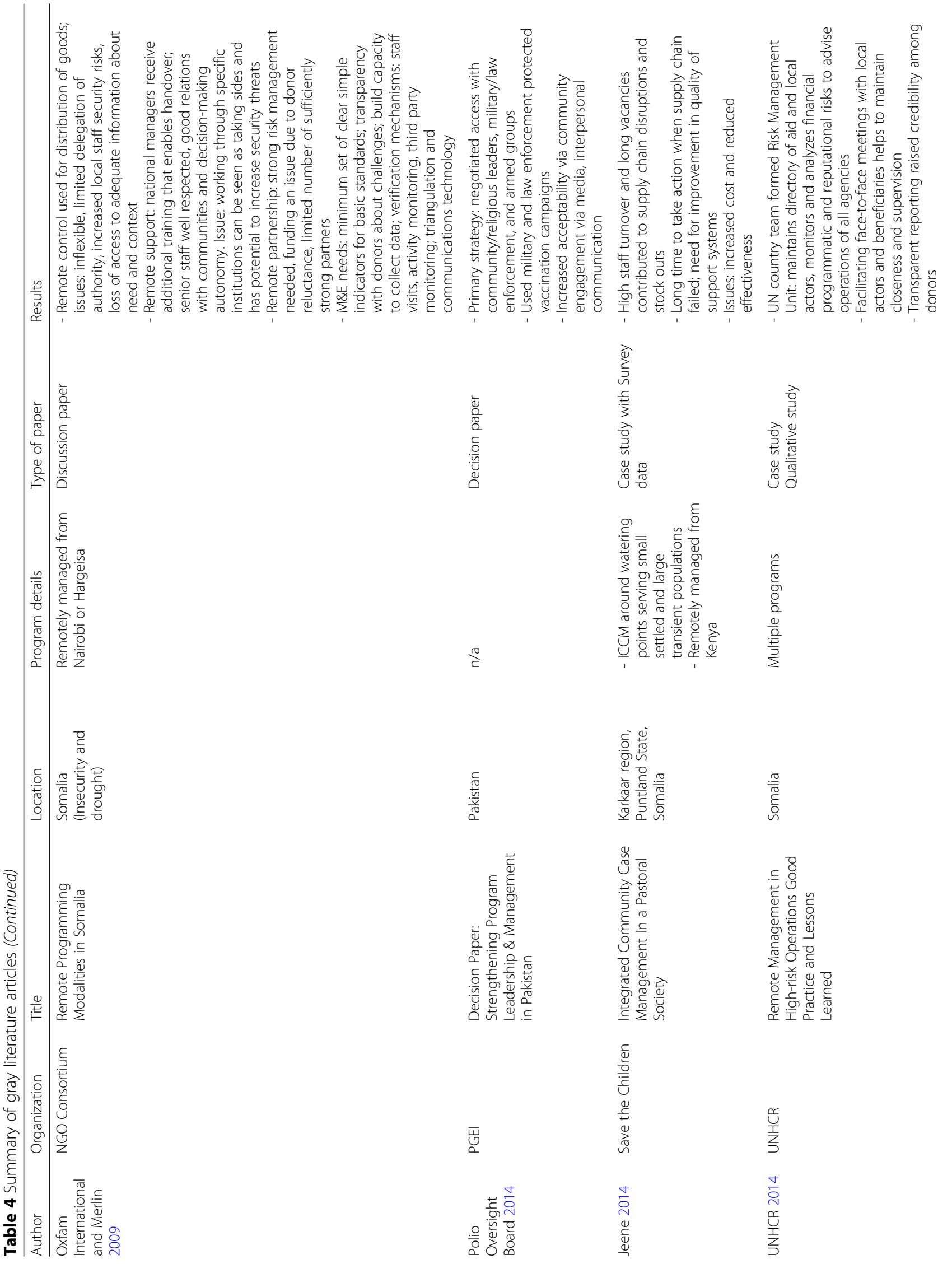




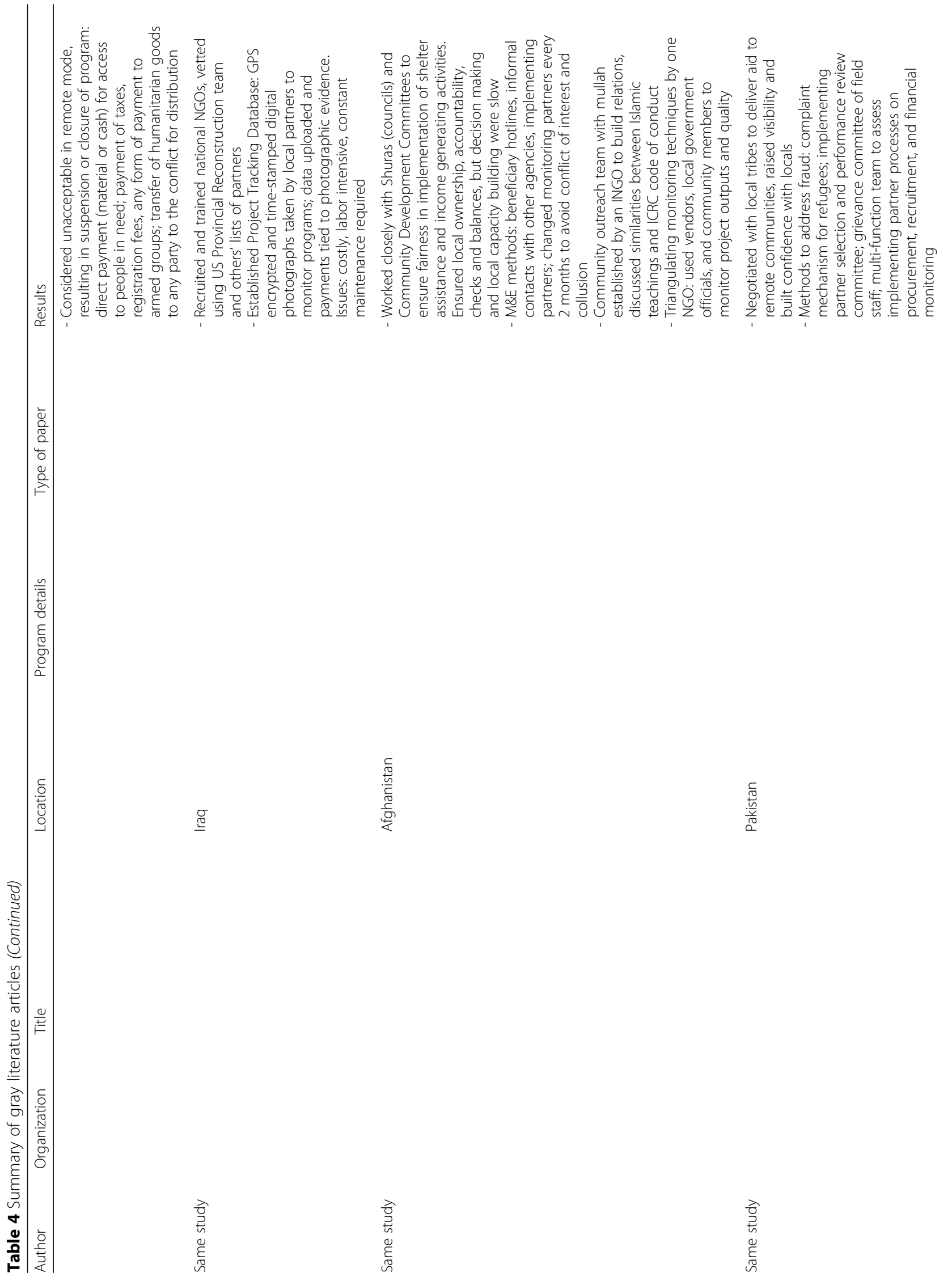




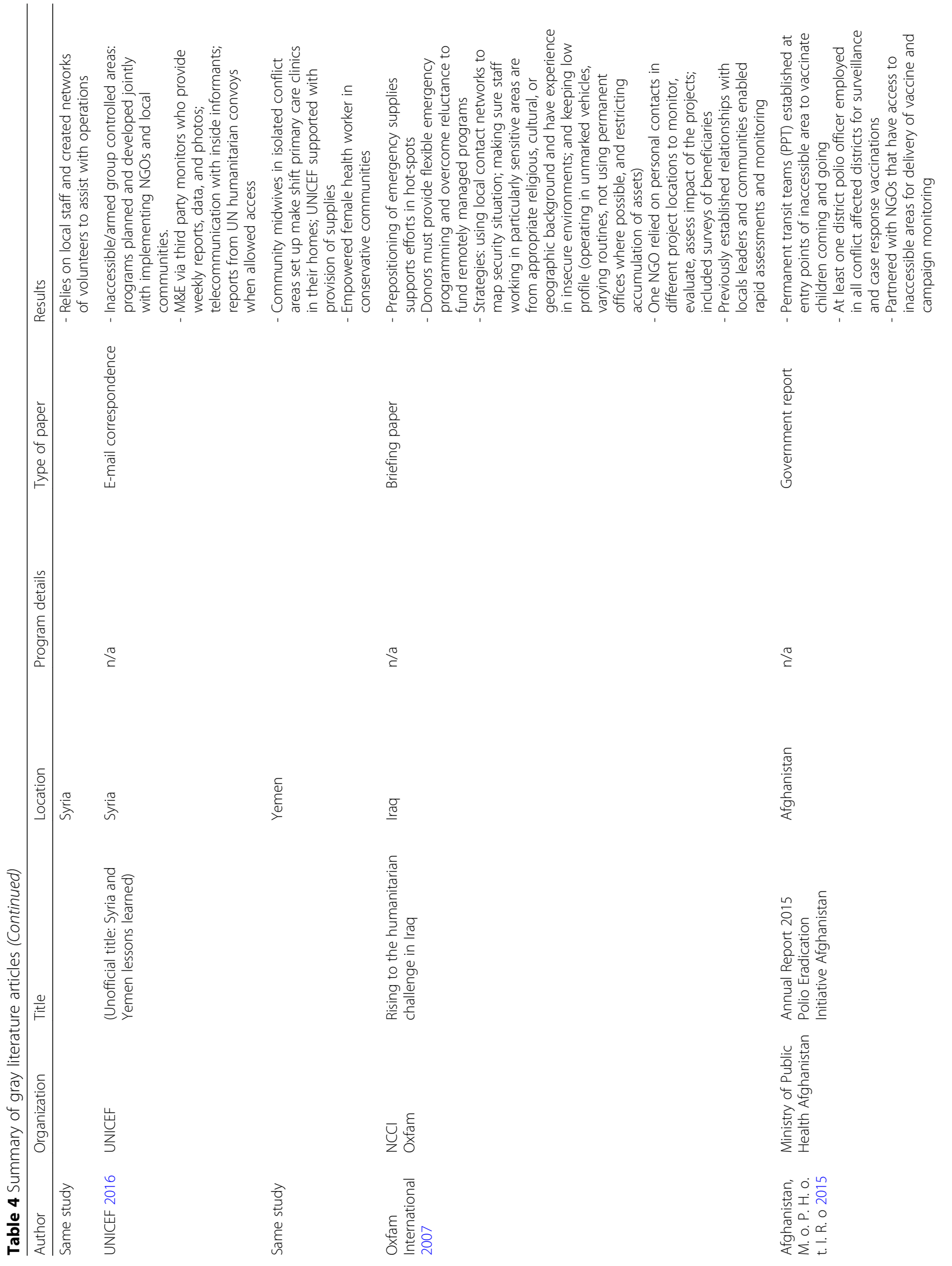




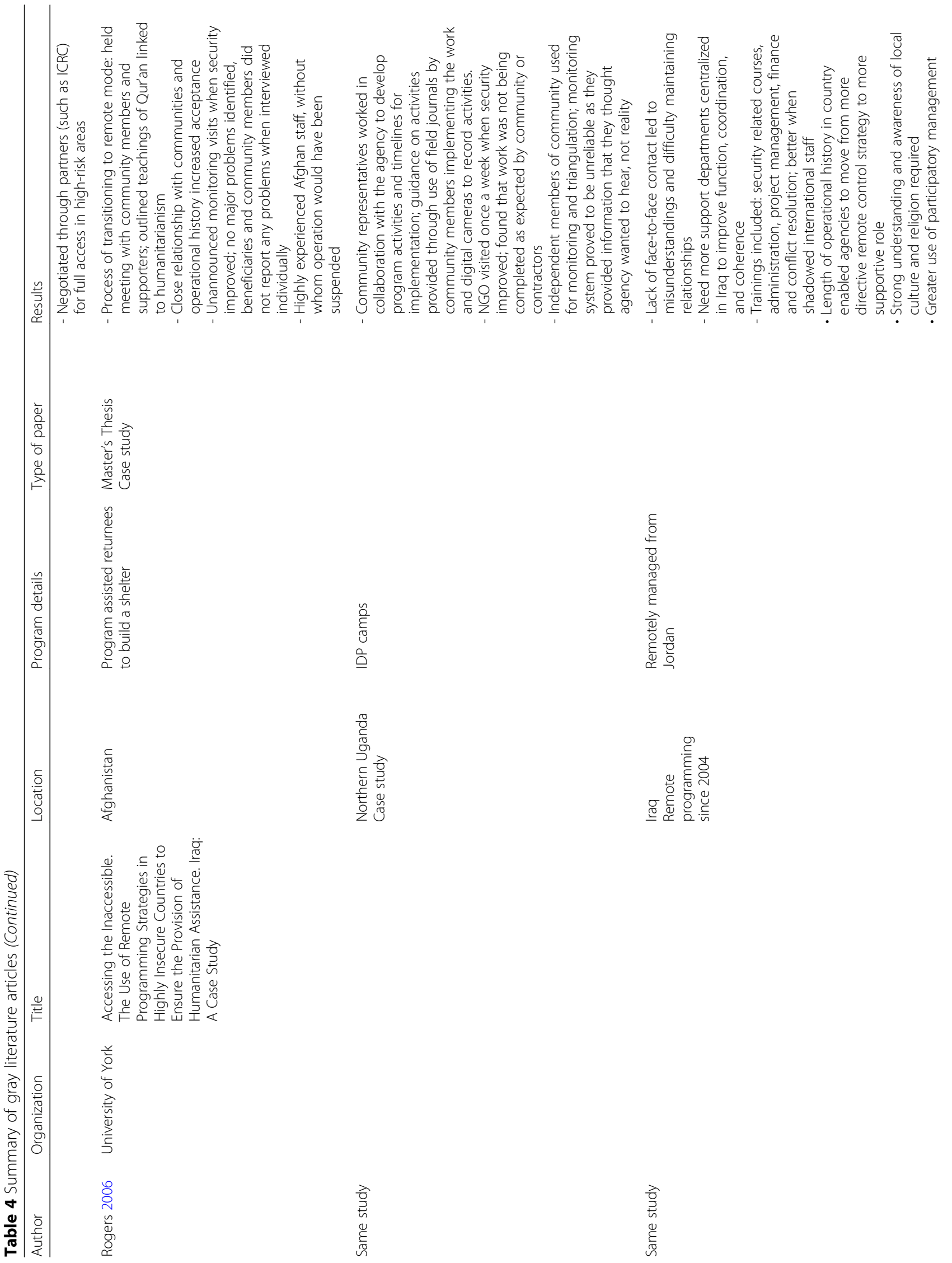




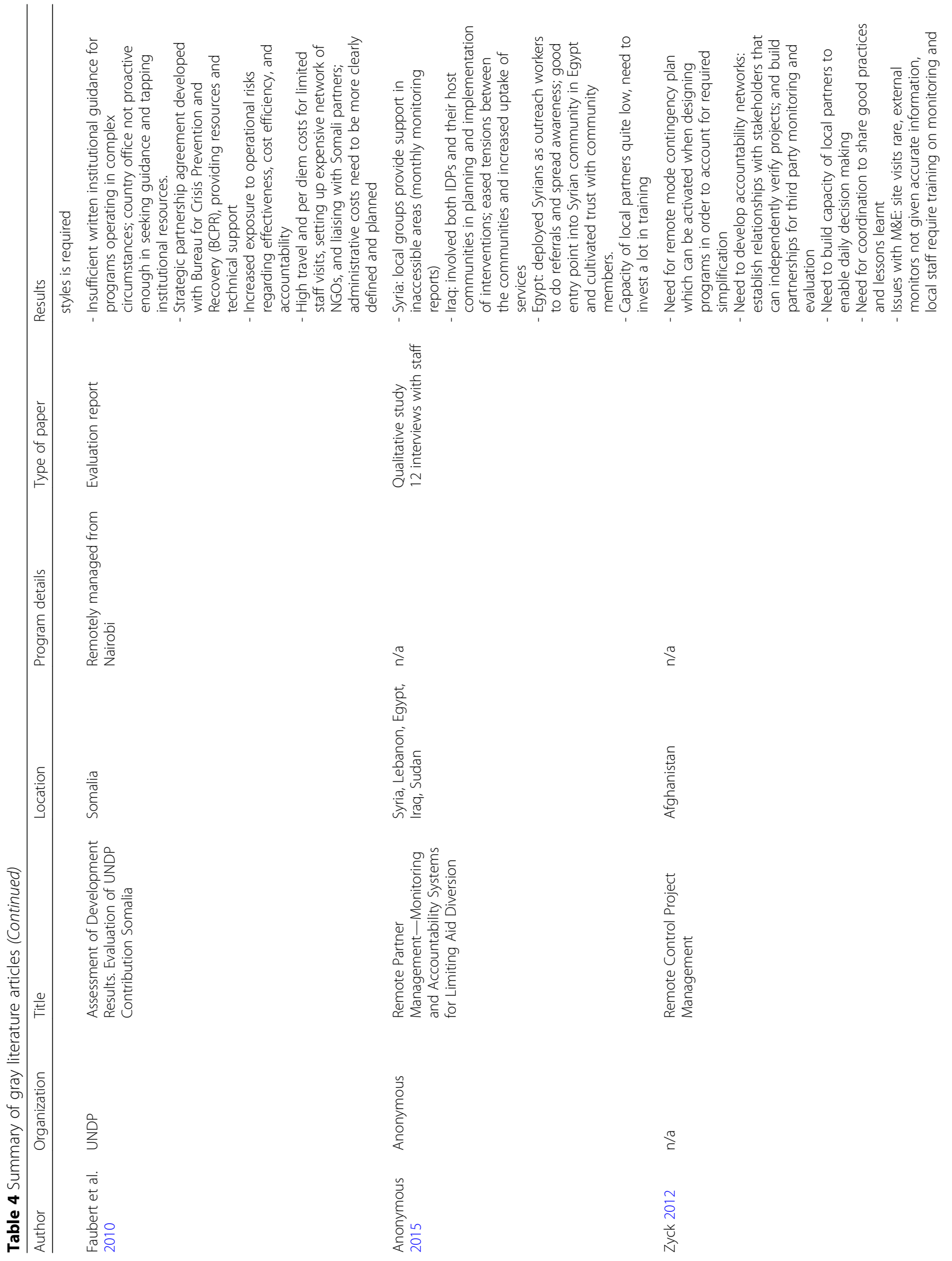




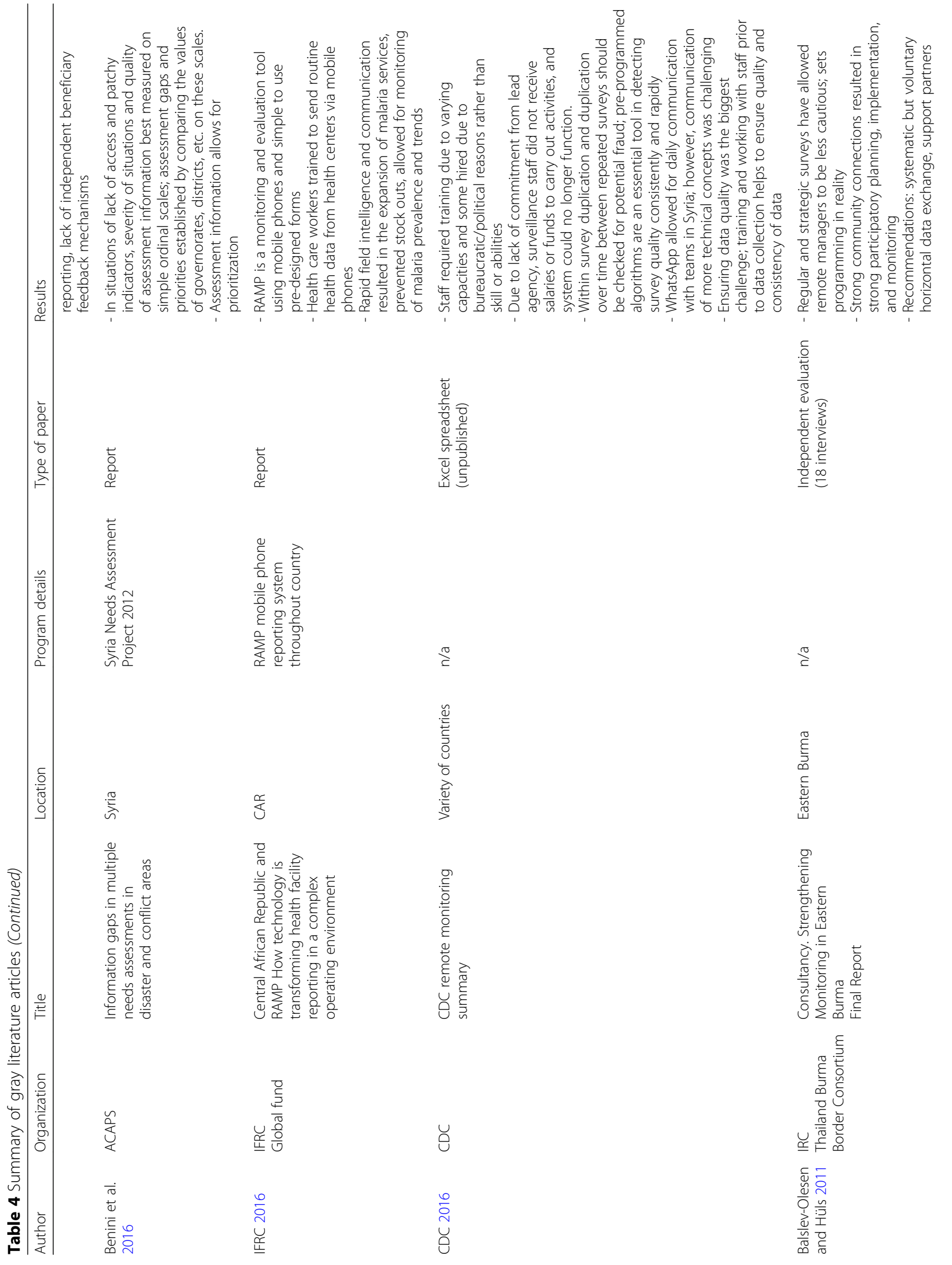




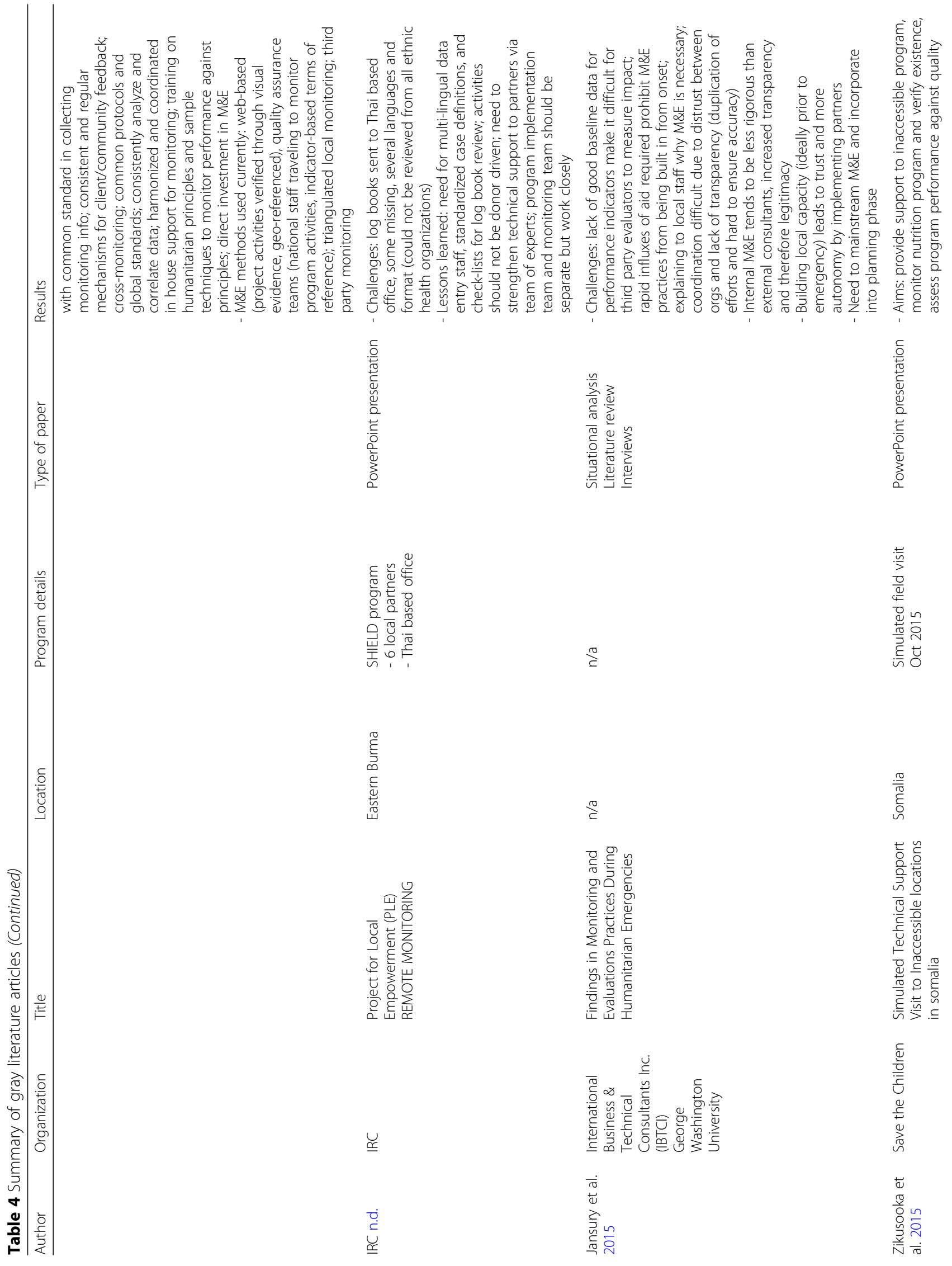




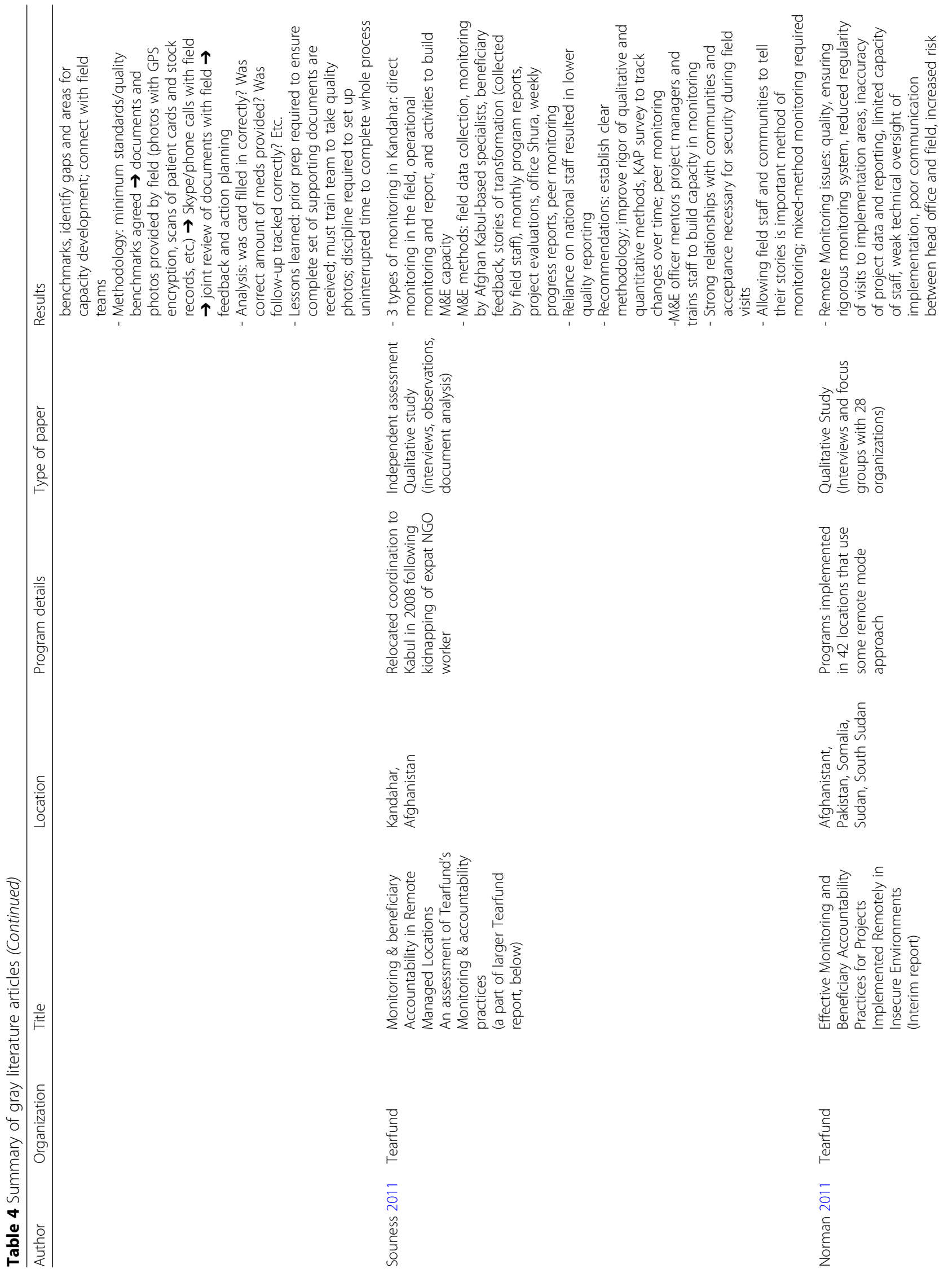




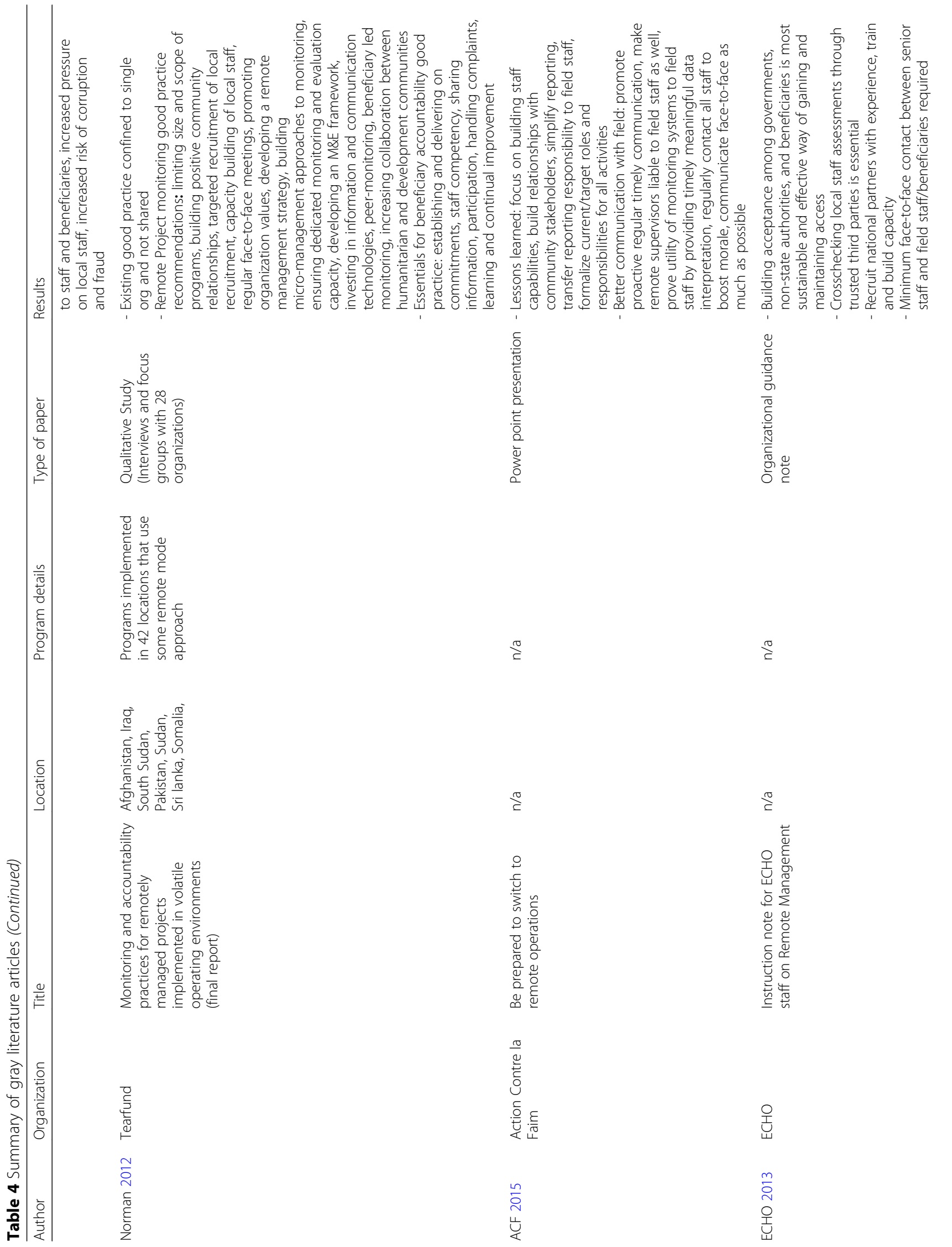




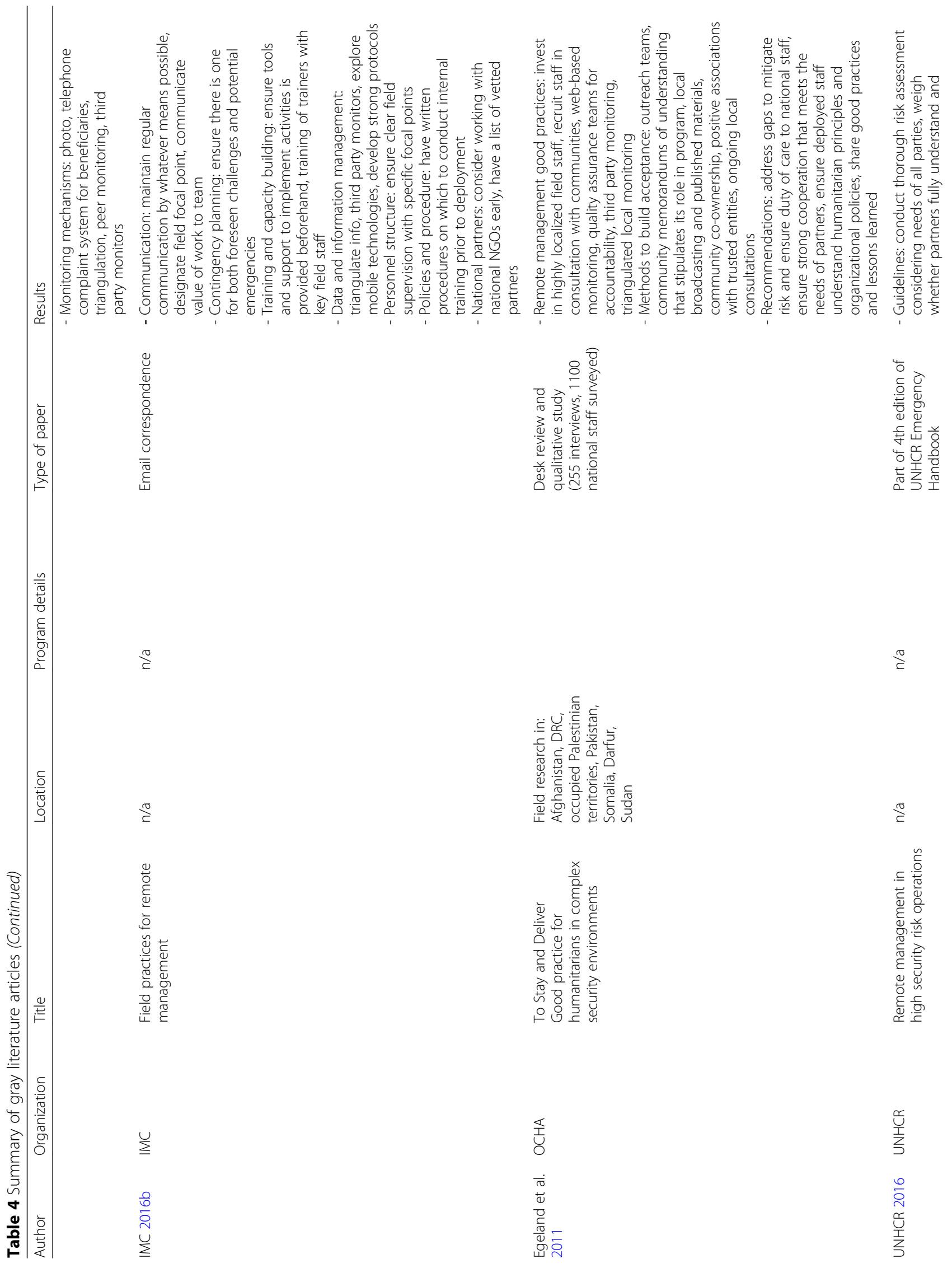




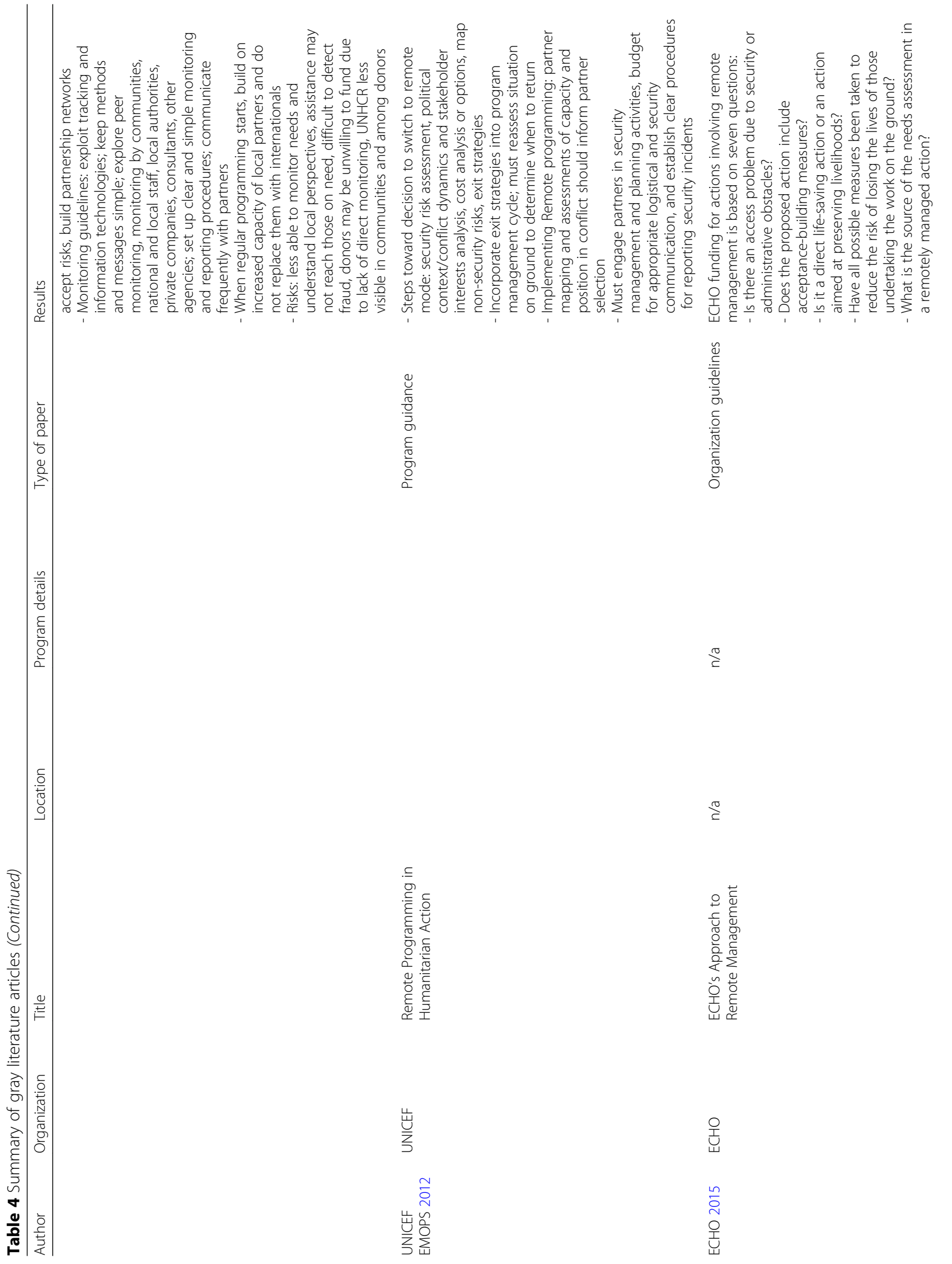




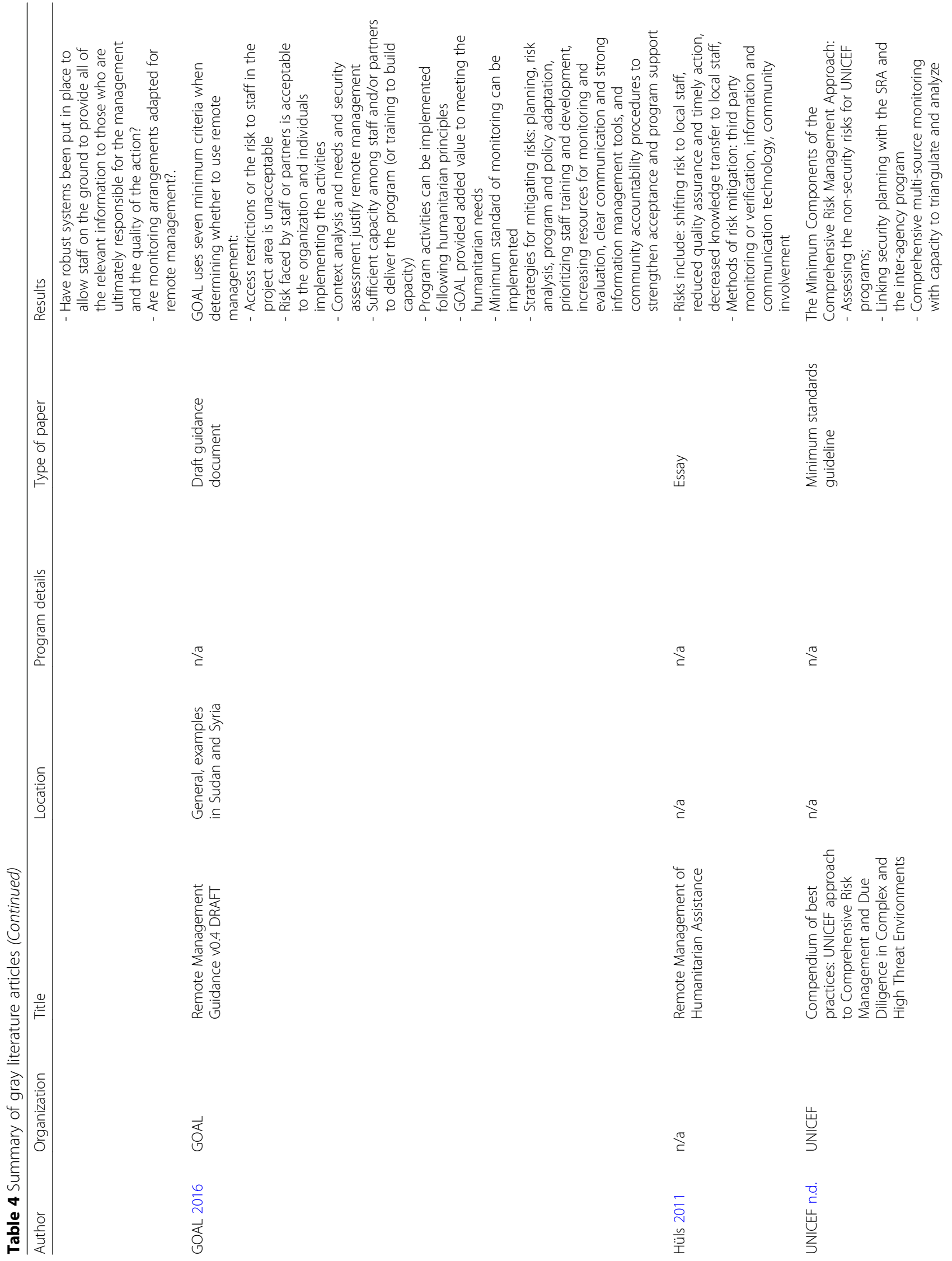




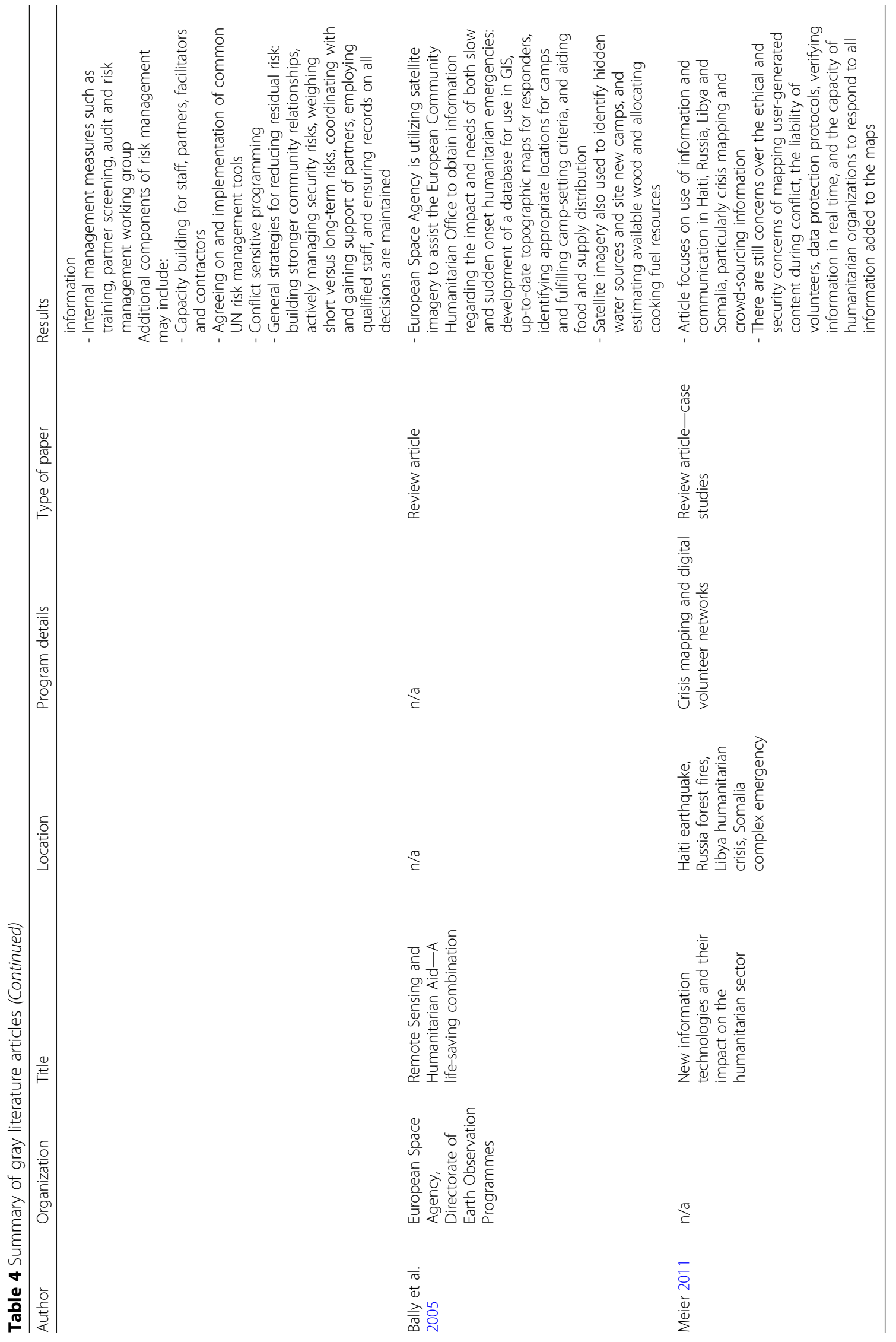




\section{Recommendations}

Despite this major drawback in evidence quality, it is important to acknowledge that emergency conflict settings, especially those that are inaccessible, are not conducive to data collection generally, with randomized controlled trials being especially difficult. This is true for a number of reasons including security concerns, ethical considerations, limited resources, and the urgency with which humanitarian aid needs to be delivered, and remains one of the core challenges to improving the evidence needed to improve remote operations. Nevertheless, rigorous data collection and reporting, using both qualitative and quantitative methods, needs to become commonplace in humanitarian emergencies; it is required, not only to share lessons learned but also to promote critical analysis of methods, create best practice guidelines, and root humanitarian action firmly in evidence.

Implementation studies are urgently needed to identify factors that make certain remote programming and monitoring activities more effective than others, and what factors hinder their success. Implementation science methods that collect process and outcome indicators while taking a detailed look at settings and constraints can be used to elucidate what can and cannot be replicated through a variety of humanitarian conflict settings and assess key issues such as cost and sustainability.

Qualitative studies focusing on beneficiary and national/local staff perspectives are required to ensure that remote humanitarian programming is tailored to the true needs of the affected population and designed with the implementers' and affected populations' preferences in mind. Incorporating implementer perspectives from program onset not only facilitates efficient delivery but also highlights their value, potentially contributing to a more equitable distribution of power.

Finally, rigorous research and evaluation of remote programs should be undertaken to answer questions such as:

- What are the best practices that should be adopted by agencies carrying out remote operations?

- How effective are various remote operations interventions, guidelines, and tools when implemented in different contexts?

- What are feasible and effective methods of monitoring and evaluating remote programs?

- What are the key criteria for vetting local partners or local staff to help ensure adherence to humanitarian standards?

- What are the critical needs and challenges identified by local partners implementing programs in conflict settings? What support is needed from their remote partner?

- What is the assessment of remote interventions from the point of view of the affected populations?

\section{Conclusions}

This review highlights the paucity of evidence on how to effectively carry out remote programming and monitoring. Considering the increasingly challenging environments in which humanitarian actors are working, there is an urgent need for evidence-based guidelines and tools. We can identify key principles for operating remotely, including the importance of capacity building and frequent communication, comprehensively assessing and addressing the risks faced by national staff, increasing the intensity and resources of M\&E efforts despite the difficult conditions, and planning for the possibility of having to move to remote programming and having an exit strategy to prevent falling into the remote operations trap. To further build the evidence base, we encourage those implementing remote programs to rigorously document and evaluate their work and to share the findings. The current climate of increasing conflicts and risk to humanitarian aid workers necessitates evidence-based strategies to ensure both the safety of those delivering aid in these harsh conditions and that quality programming reaches those they are there to serve.

\section{Endnotes}

${ }^{1}$ While this was originally referred to as the "remote management trap" in the literature, it has been changed to 'remote operations trap' to maintain consistency with the terminology used throughout this report.

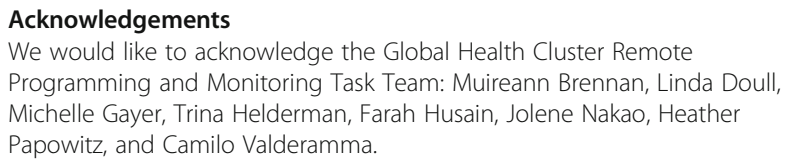

No financial or other material support was received for this work.

Availability of data and materials

Data sharing is not applicable to this article as no datasets were generated or analyzed during the current study.

Authors' contributions

SC and KC analyzed, interpreted, and synthesized the review data. SC and KC wrote the manuscript. SC, KC, and NM, read, edited, and approved the final manuscript.

Competing interests

The authors declare that they have no competing interests.

\section{Publisher's Note}

Springer Nature remains neutral with regard to jurisdictional claims in published maps and institutional affiliations.

Author details

${ }^{1}$ UNICEF New York 3 United Nations Plaza, New York, NY 10017, USA. ${ }^{2}$ Center for Disease Control and Prevention, 1600 Clifton Rd, Atlanta, GA 30333, USA. 
Received: 1 July 2018 Accepted: 7 March 2019

\section{Published online: 08 April 2019}

\section{References}

Secure Access in Volatile Environments (SAVE) (2016). Briefing Note, April 2016. Retrieved from

ACF (2015) Be prepared to switch to remote operations (presentation). Action Contre La Faim, Paris

Ministry of Public Health of the Islamic Republic of Afghanistan (2015). Annual Report 2015 Polio Eradication Initiative Afghanistan.

Aid Worker Security Database. (2014). Major attacks on aid workers: summary statistics (2004-2014). Retrieved from https://aidworkersecurity.org/incidents/ report/summary

Andersson R, Weigand F (2015) Intervention at risk: the vicious cycle of distance and danger in Mali and Afghanistan. J Int Statebuilding 9(4):519-541. https:// doi.org/10.1080/17502977.2015.1054655

Anonymous. (2015). Remote partner management-monitoring and accountability systems for limiting aid diversion

Balfour N (2015) CLTS in fragile and insecure contexts. Pract Action Publ 34(3):7. https://doi.org/10.3362/1756-3488.2015.025

Bally, P., Béquignon, J., Arino, O., Briggs, S. (2005). Remote sensing and humanitarian aid-a life-saving combination. Retrieved from Italy:

Balslev-Olesen, C., Hüls, V. (2011). Consultancy. Strengthening monitoring in eastern Burma. Final report. Retrieved from Denmark:

Belliveau, J. (2013). 'Remote management' in Somalia. Humanitarian Exchange

Benini, A., Chataigner, P., Noumri, N., Tax, L., Wilkins, M. (2016). Information gaps in multiple needs assessments in disaster and conflict areas. Retrieved from

Bharti N, Lu X, Bengtsson L, Wetter E, Tatem AJ (2015) Remotely measuring populations during a crisis by overlaying two data sources. Int Health 7(2): 90-98. https://doi.org/10.1093/inthealth/ihv003

Blanchet, K., Roberts, B. (2015). An evidence review of research on health interventions in humanitarian crises. Retrieved from

CASP. (2013). Qualitative research checklist. Retrieved from http://media.wix.com/ ugd/dded87_29c5b002d99342f788c6ac670e49f274.pdf

CDC (2008) Progress toward poliomyelitis eradication-Pakistan and Afghanistan, 2007. MMWR Morb Mortal Wkly Rep 57(12):315-319

CDC (2016) Remote monitoring summary. CDC, Atlanta

Chu KM, Ford NP, Trelles M (2011) Providing surgical care in Somalia: a model of task shifting. Confl Heal 5:12-12. https://doi.org/10.1186/1752-1505-5-12

Collinson, S., Duffield, M. (2013). Paradoxes of presence. Risk management and aid culture in challenging environments. Retrieved from London, UK

Cunningham, A. (2016). To stay and deliver? The Yemen Humanitarian Crisis 2015. Retrieved from

Cunningham AJ (2017) Kidnapping and the limits of acceptance. J Int Humanit Action 2(1):4. https://doi.org/10.1186/s41018-017-0020-5

Donini A, Maxwell D (2013) From face-to-face to face-to-screen: remote management, effectiveness and accountability of humanitarian action in insecure environments. Int Rev Red Cross 95(890):383-413. https://doi.org/10 $1017 /$ S1816383114000265

Duffield M (2012) Challenging environments: danger, resilience and the aid industry. Security Dialogue 43(5):475-492. https://doi.org/10.1177/ 0967010612457975

ECHO. (2013). Instruction note for ECHO staff on remote management. Retrieved from Belgium:

ECHO. (2015). ECHO's approach to remote management. Retrieved from Brussels: Egeland, J., Harmer, A., Stoddard, A. (2011). To stay and deliver. Good Practice for humanitarians in complex security environments. Retrieved from USA:

Emmens, B., Clayton, M. (2017). Localisation of aid: are INGOs walking the talk? Retrieved from https://reliefweb.int/sites/reliefweb.int/files/resources/WTT_ FINAL.pdf

Enenkel M, See L, Karner M, Alvarez M, Rogenhofer E, Baraldes-Vallverdu C et al (2015) Food security monitoring via mobile data collection and remote sensing: results from the Central African Republic. PLoS One 10(11). https:// doi.org/10.1371/journal.pone.0142030

Faubert, C., Bhattacharjee, A., Ekuam, D. (2010). Assessment of development results evaluation of UNDP contribution Somalia. Retrieved from USA:

Fisher J (2017) Reproducing remoteness? States, internationals and the co-constitution of aid 'bunkerization' in the east African periphery. J Interv Statebuilding 11(1):98-119. https://doi.org/10.1080/17502977. 2016.1260209
Gates, S., Nygård, H., Strand, H., Urdal, H. (2016). Trends in Armed Conflict, 1946-2014. Conflict Trends Project (Peace Research Institute Oslo - PRIO) GOAL. (2016). Remote Management Guidance v0.4 DRAFT. Retrieved from Hammond, L., Vaughan-Lee, H. (2012). Humanitarian space in Somalia: a scarce commodity. Retrieved from United Kingdom:

Hansen, G. (2008a). Adapting to Insecurity in Iraq. Retrieved from Amman: Hansen, G. (2008b). Operational Modalities in Iraq. Retrieved from Amman: Herbert, S. (2013). Remote management of projects in fragiel states. Retrieved from Birmingham, UK:

Howe, K., Stites, E., Chudacoff, D. (2015). Breaking the Hourglass: partnerships in remote management settings - the cases of Syria and Iraqi Kurdistan. Retrieved from USA:

Hüls, V. (2011). Remote Management of Humanitarian Assistance. Retrieved from http://lawanddevelopment.org/articles/remotemanagement.html

IFRC. (2016). Central African Republic and RAMP how technology is transforming health facility reporting in a complex operating environment. Retrieved from Geneva

IMC (2016a). [Details from IMC Somalia Programming (Email communication)] IMC (2016b). [Field Practices for remote management (email)]

IOM. (2008). Programme management by 'remote control'

IRC (n.d.) Project for local empowerment (PLE) remote monitoring. IRC, New York

Jansury, L., Moore, J., Peña, J., Price, A. (2015). Findings in monitoring and evaluation practices during humanitarian emergencies. Retrieved from

Jeene, H. (2014). Integrated community case management in a pastoral society. karkaar Region, Puntland State, Somalia 2014. Retrieved from

Kalkman JP (2018) Practices and consequences of using humanitarian technologies in volatile aid settings. J Int Humanit Action 3(1):1. https://doi. org/10.1186/s41018-018-0029-4

Kevany S, Sahak O, Workneh NG, Saeedzai SA (2014) Global health diplomacy investments in Afghanistan: adaptations and outcomes of global fund malaria programs. Med, Confl Surviv 30(1):37-55

Kjaerum, A. (2015). Remote management in humanitarian operations. Retrieved from Denmark:

Krystalli, R. (2017). Four lessons learned from synthesising humanitarian evidence. Retrieved from https://www.alnap.org/blogs/four-lessons-learned-fromsynthesising-humanitarian-evidence

Lee TJ, Mullany LC, Richards AK, Kuiper HK, Maung C, Beyrer C (2006) Mortality rates in conflict zones in Karen, Karenni, and Mon states in eastern Burma. Tropical Med Int Health 11(7):1119-1127. https://doi.org/10.1111/j.1365-3156. 2006.01651.x

Mahn M, Maung C, Oo EK, Smith L, Lee Cl, Whichard E et al (2008) Multi-level partnerships to promote health services among internally displaced in eastern Burma. Glob Public health 3(2):165-186

Martinez-Garcia D (2014) A retrospective analysis of pediatric cases handled by the MSF tele-expertise system. Front Public Health 2(266). https://doi.org/10. 3389/fpubh.2014.00266

Mattli K, Gasser J (2008) A neutral, impartial and independent approach: key to ICRC's acceptance in Iraq. Int Rev Red Cross 90(869):153-168

Meier P (2011) New information technologies and their impact on the humanitarian sector. Int Rev Red Cross 93(884):1239-1263

$\mathrm{NIH}$. (2014). Quality assessment tool for case series studies. Retrieved from http:// www.nhlbi.nih.gov/health-pro/guidelines/in-develop/cardiovascular-riskreduction/tools/case_series

Norman, B. (2011). Effective monitoring and beneficiary accountability practices for projects implemented remotely in insecure environments. Interim Research Report. Retrieved from

Norman, B. (2012). Monitoring and accountability practices for remotely managed projects implemented in volatile operating environments. Retrieved from

OCHA. (2012). What are Humanitarian Principles? Retrieved from https://docs. unocha.org/sites/dms/Documents/OOM-humanitarianprinciples_eng_June12. pdf

Oxfam International. (2007). Rising to the humanitarian challenge in Iraq. Retrieved from United Kingdom:

Oxfam International, \& Merlin. (2009). Remote Programming Modalities in Somalia Discussion Paper. Retrieved from

Polio Oversight Board. (2014). Decision paper: strengthening program leadership \& management in Pakistan. Retrieved from

Richard AJ, Lee Cl, Richard MG, Oo EK, Lee T, Stock L (2009) Essential trauma management training: addressing service delivery needs in active conflict zones in eastern Myanmar. Hum Resour Health [Electronic Resource] 7:19 
Rivas, A.-M. (2015). No longer a last resort: a review of the remote programming landscape. Retrieved from

Rogers C (2006) Accessing the inaccessible. The use of remote programming strategies in highly insecure countries to ensure the provision of humanitarian assistance. Iraq: a case study. (Master of Arts in Post-war Recovery Studies), The University of York, York

Schreter L, Harmer A (2013) Delivering aid in highly insecure environments. In: A critical review of the literature, 2007 - 2012 Retrieved from

Shanks L, Masumbuko EW, Ngoy NM, Maneno M, Bartlett S, Thi SS, Shah T (2012) Treatment of multidrug-resistant tuberculosis in a remote, conflict-affected area of the Democratic Republic of Congo. Int J Tuberc Lung Dis 16(8):10661068. https://doi.org/10.5588/ijtld.11.0240

Souness, C. (2011). Monitoring \& benefriciary accountability in remote managed locations. Retrieved from

Steets, J., Reichhold, U., Sagmeister, E. (2012). Evaluation and review of humanitarian access strategies in DG ECHO funded interventions. Retrieved from Berlin, Germany:

Stoddard, A., Harmer, A., DiDomenico, V. (2009). Providing aid in insecure environments: 2009 update. Retrieved from London, UK.

Stoddard, A., Harmer, A., Haver, K. (2006). Providing aid in insecure environments: trends in policy and operations. Retrieved from London, UK:

Stoddard, A., Harmer, A., Renouf, J. (2010). Once removed. Lessons and challenges in remote management of humanitarian operations for insecure areas. Retrieved from London, UK

Tong J, Valverde O, Mahoudeau C, Yun O, Chappuis F (2011) Challenges of controlling sleeping sickness in areas of violent conflict: experience in the Democratic Republic of Congo. Confl Heal 5:7-7. https://doi.org/10.1186/ 1752-1505-5-7

UNHCR. (2014). Remote management in high-risk operations good practices and lessons learned. Retrieved from USA:

UNHCR. (2016). Remote management in high security risk operations. Retrieved from USA:

UNICEF (2016). [Email from country office: Syria and Yemen Lessons Learned]

UNICEF. (n.d.). (SHA4) Compendium of best practices: UNICEF approach to comprehensive risk management and due diligence in complex and high threat environments. Retrieved from New York.

UNICEF EMOPS (2011a) UNICEF and remote programming: Afghanistan case study, EMOPS Guidance on Remote Programming Background Papers. UNICEF, New York

UNICEF EMOPS (2011b) UNICEF and remote programming: Iraq case study, EMOPS Guidance on Remote Programming Background Papers. UNICEF, New York

UNICEF EMOPS (2011c) UNICEF and remote programming: Pakistan case study, EMOPS guidance on Remote Programming Background Papers. UNICEF, New York

UNICEF EMOPS (2011d) UNICEF and remote programming: Somalia case study, EMOPS Guidance on Remote Programming Background Papers. UNICEF, New York

UNICEF EMOPS. (2012). Remote programming in humanitarian action. Retrieved from USA:

Zachariah, R., Bienvenue, B., Ayada, L., Manzi, M., Maalim, A., Engy, E., . . Harries, A. D. (2012). Practicing medicine without borders: tele-consultations and telementoring for improving paediatric care in a conflict setting in Somalia? Tropical Med Int Health, 17(9), 1156-1162. doi:https://doi.org/10.1111/j.13653156.2012.03047.x

Zikusooka M, Mose R, Donnelly A (2015) Simulated technical support visit to inaccessible locations in Somalia: Save the children

Zyck, S. (2012). Remote Control Project Management. Retrieved from

\section{Submit your manuscript to a SpringerOpen ${ }^{\circ}$ journal and benefit from:}

- Convenient online submission

- Rigorous peer review

- Open access: articles freely available online

- High visibility within the field

- Retaining the copyright to your article

Submit your next manuscript at $\boldsymbol{\nabla}$ springeropen.com 